
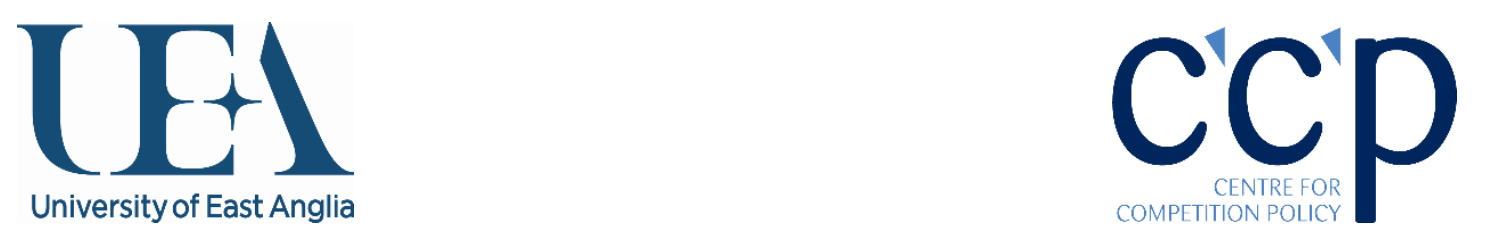

\title{
Energy Affordability in the UK: Corrected Energy Expenditure Shares 1992-2014
}

\author{
David Deller \\ Centre for Competition Policy \\ University of East Anglia \\ Catherine Waddams Price \\ Centre for Competition Policy \\ Norwich Business School \\ University of East Anglia \\ CCP Working Paper 18-8
}

\begin{abstract}
The retail energy market in the UK is highly politicised and since the turn of the millennium successive governments have pursued significant policies designed to ease the affordability of energy for certain groups. One of these policies, namely Winter Fuel Payments, represent both a significant increase in resources targeted at affordability support and a shift in emphasis from those on low incomes towards the elderly. This paper tracks the proportion of household expenditure devoted to energy between 1992 and 2014, implementing a major new correction to energy expenditure for households with prepayment meters, who tend to be low income households. First, the time series is used to argue that the political salience of distributional concerns in the retail energy market should not come as a surprise. Second, we find that while households with a head aged over 80 have elevated energy expenditure shares (similar to households at the bottom of the income distribution), pensioners aged 65-70 have energy expenditure shares comparable to households at the middle of the income distribution. Third, mapping major policy developments against the time series shows the most generous and ambitious affordability support schemes were introduced when energy was nearing its most affordable over a 35-year period, suggesting political considerations influenced both the recipients of support and the timing of interventions.
\end{abstract}

Contact Details:

David Deller

david.deller@uea.ac.uk 


\title{
Energy Affordability in the UK: Corrected Energy Expenditure Shares 1992- 2014
}

\author{
David Deller and Catherine Waddams Price ${ }^{1}$ \\ Centre for Competition Policy, University of East Anglia
}

\begin{abstract}
August 2018
Abstract The retail energy market in the UK is highly politicised and since the turn of the millennium successive governments have pursued significant policies designed to ease the affordability of energy for certain groups. One of these policies, namely Winter Fuel Payments, represent both a significant increase in resources targeted at affordability support and a shift in emphasis from those on low incomes towards the elderly. This paper tracks the proportion of household expenditure devoted to energy between 1992 and 2014, implementing a major new correction to energy expenditure for households with prepayment meters, who tend to be low income households. First, the time series is used to argue that the political salience of distributional concerns in the retail energy market should not come as a surprise. Second, we find that while households with a head aged over 80 have elevated energy expenditure shares (similar to households at the bottom of the income distribution), pensioners aged 65-70 have energy expenditure shares comparable to households at the middle of the income distribution. Third, mapping major policy developments against the time series shows the most generous and ambitious affordability support schemes were introduced when energy was nearing its most affordable over a 35-year period, suggesting political considerations influenced both the recipients of support and the timing of interventions.
\end{abstract}

\section{Introduction}

Distributional issues and fairness have been a recurrent theme in the British retail energy market ${ }^{2}$, particularly since privatisation was completed in the early 1990s. These concerns arise because low income households, on average, devote a greater proportion of their household expenditure to energy than other households. To address this issue, successive governments have introduced a range of affordability support policies, including the Cold Weather Payment, a Fuel Poverty Strategy (FPS), the Winter Fuel Payment (WFP) and the Warm Home Discount (WHD). We trace the proportion of expenditure devoted to energy by different household groups between 1992 and 2014, focusing particularly on pensioners, and households in the lowest income deciles, to place these political concerns and the resulting policy responses in context.

The paper provides the most extensive mapping of energy expenditure shares (ENEXShr) across UK households to date. We apply a new correction to a serious measurement issue regarding prepayment meter (PPM) energy expenditures (ENEX) in the Living Cost and Food Survey ${ }^{3}$ (LCF). The present paper extends existing work in a number of other ways. ENEX and ENEXShr are mapped across an unusually wide range of household characteristics, providing both a cross-section and a historical perspective. These data enable a comparison of groups receiving substantial government support on

\footnotetext{
${ }^{1}$ Corresponding author: Dr David Deller, Centre for Competition Policy, University of East Anglia, Norwich Research Park, Norwich, Norfolk, NR4 7TJ, email: david.deller@uea.ac.uk. The extensive support of Research Associate Glen Turner is gratefully acknowledged. This research was undertaken as part of the UK Energy Research Centre (UKERC) research programme. We also thank Kai-Uwe Kuhn, members of CCP's UKERC project team and participants in the CCP Seminar, CCP Annual Conference 2017 and the 6th Mannheim Energy Conference for their comments.

${ }^{2}$ Most recently these concerns have been demonstrated through legislation being passed for a price cap to 'protect' 'inactive' consumers, see Domestic Gas and Electricity (Tariff Cap) Act, 2018 available at: http://www.legislation.gov.uk/ukpga/2018/21/contents/enacted/data.htm

3 and its precursors
} 
energy affordability grounds and those who devoted the greatest proportion of their expenditure to energy. They also chart the apparently counter-intuitive development of affordability support policies, especially the WFP and the FPS, at a time when ENEXShr was approaching a historically low rather than high level.

Despite ENEXShr falling at the time, the WFP was introduced in 1997, and its level increased significantly during the early 2000s, when ENEXShr was at a long-term low. Similarly, the first FPS was introduced in 2001, and the period's relatively easy energy affordability helps explain both its initially ambitious eradication target and the need to revise this target as energy affordability pressures rose. We note that the changing political ideology of governments likely contributed to this story, with many policies being initiated by the Labour government elected in 1997, and revision of the FPS and the measurement of Fuel Poverty (FP) by the Conservative-Liberal coalition after 2010. While scope for affordability support may have been constrained by tighter fiscal limits after the 2008 Financial Crisis, , governments still retained discretion over where to deploy their limited funds.

Since the 1990s, both policy action on FP and the related literature ${ }^{4}$ have expanded considerably. While contributing to the FP literature, the present paper explores energy affordability as a wider issue than the traditional statistical FP definitions, by mapping ENEX and ENEXShr distributions across households. We track developments in the FPS as a proxy for variations in the political emphasis given to energy affordability support, the FPS has mostly focused on efforts to improve the energy efficiency of the housing stock. For a detailed discussion of FP measurement see Deller and Waddams Price (2018), which uses the corrected ENEX time series from the present paper to compare rates of FP in England based on reported ENEX with the official FP statistics based on 'required' (or modelled) ENEX.

Our historical mapping also places recent ENEXShr in a historical context: while ENEXShr since 2009 are high compared to the early 2000s, real ENEX and ENEXShr values are similar to those in the late 1980s and early 1990s. However, following a period of remarkable stability between 1992 and 20034, nominal ENEX doubled in the following decade, contributing to consumers' perceptions of continuously rising energy prices and adding to the pressure for intervention in the market, which culminated in the introduction of price caps in 2017 and18.

The ENEXShr and ENEX patterns, which influence the political salience of the retail energy market, arise from the inelasticity of the product with respect to both income and price, reflecting energy's characteristic as a necessity ${ }^{5}$. Inelastic demand explains both why lower income groups have higher ENEXShr and the positive correlation of ENEXShr with energy prices through time. The median equivalised after-housing-costs ENEXShr ${ }^{6}$ in 2014 for the lowest income decile ${ }^{7}$ was almost two and a half times that for the highest income decile; and between 2003-04 and 2014 the increase in the lowest income decile's median ENEXShr was almost two and a half times that of the richest group. This highlights the significant variation in the proportionate welfare impact of rising energy prices by income level: while for those at the top of the income distribution rising ENEX may have been inconvenient, for those with the lowest disposable income it implied serious budget choices. Similarly declining ENEXShr during the 1990s provided greater proportionate welfare gains to those at the

\footnotetext{
${ }^{4}$ Isherwood and Hancock (1979) and Boardman (1991) are early works on this topic.

${ }^{5}$ For example, Dimitropoulos et al (2005) estimate the long-run price elasticity of residential energy in the UK to be -0.23 and the long-run income elasticity to be 0.34 .

${ }^{6}$ All references to ENEXShr in this paper use this definition unless stated otherwise.

${ }^{7}$ All references to income deciles in this paper refer to the equivalised after-housing-costs income distribution unless stated otherwise.
} 
lower end of the income distribution. These changes help explain why energy has become a lightning rod for political and media comment as concerns about economic inequalities have risen.

We analyse ENEXShr by a number of household characteristics, focusing on income decile and age of household head in the main text. While ENEXShr for households headed by someone over the age of 80 are similar to those of households in the bottom third of the income distribution, the ENEXShr of younger pensioner households (i.e. those with a head aged 65-70) generally lie around the fifth income decile or above, i.e. they are equivalent to those in the middle of the income distribution. We note that across the various household categories, higher ENEXShr tends to result from lower total expenditure (income) rather than higher ENEX. This suggests that if the aim is to improve households' welfare, rather than simply altering ENEXShr statistics, energy-specific interventions may be less important than efforts to resolve general income poverty.

The next section reviews relevant literature, while Section 3 discusses our data and methodology, incorporating the data correction for PPM users. Section 4 reports aggregate results over time and presents evidence on ENEXShr by income and age. These findings are used to discuss the timing and direction of affordability support policies in Section 5 , before Section 6 concludes. Appendix 1 provides additional mappings of ENEX and ENEXShr by age, housing tenure, household composition and UK nation.

\section{Existing Literature}

The current paper builds on the methodology and policy detail of Advani et al. (2013) but differs in two important respects. First, an alternative correction for PPM 'zero expenditures' is applied, reflecting evidence indicating that the zeros are missing data. This correction is significant as it implies that the average ENEX for a PPM household in the uncorrected data is too low, which particularly affects low income consumers ${ }^{8}$. Second, whereas Advani et al. produce a detailed distributional analysis of energy policy in 2009-10, the current paper places this in historical context by mapping ENEXShr according to a range of household characteristics over the period 1992-2014, with additional observations in 1977, 1982 and 1987.

The issue of PPM users' zero ENEX, and the correction method used, not only affects distributional analysis of ENEX, but also likely affects earlier work analysing the distributions of household energy consumption and carbon emissions. Several publications use ENEX from the LCF and convert it into energy consumption and carbon emissions, for example Dresner and Ekins (2006), Druckman and Jackson (2008), Thumim and White (2008), Fahmy et al (2011), Gough (2011), Buchs and Schnepf (2013a), Buchs and Schnepf (2013b) and Hargreaves et al (2013). Applying our PPM correction (which increases ENEX estimates for low income households) seems likely to soften the positive relationship found between income and carbon emissions. The measurement issues with the LCF emphasise the benefits of using actual (rather than derived) energy consumption data for distributional analysis, as in Chatterton et al (2016).

The present analysis builds on Levell and Oldfield (2011), Waddams and Deller (2015) and Deller (2016) and Ofgem (2017), but departs from these earlier works by using a more sophisticated methodology to calculate ENEXShr. Levell and Oldfield investigate low income households' spending patterns, with particular reference to domestic fuels, and the current paper confirms their findings that the impact

\footnotetext{
${ }^{8}$ Averaging across 1992 to $2014,36.8 \%$ of sampled households in the bottom (equivalised after-housing-costs) income decile have a PPM for at least one fuel compared to $16.3 \%$ in the fifth income decile and $1.0 \%$ in the top income decile. One reason for this correlation is the installation of PPMs by energy firms to manage debt, see Ofgem (2016).
} 
of energy price fluctuations varies substantially by income. Levell and Oldfield find that in 2006 fuel price inflation increased the lowest income quintile's inflation rate by 1.8 percentage points, but increased the top income quintile's inflation rate by only 0.8 percentage points. If the PPM correction had been applied, Levell and Oldfield may well have found an even higher impact of fuel price inflation on the bottom income quintile's inflation rate.

Ofgem $(2017)^{9}$ charts the share of after tax income devoted to energy for the bottom and top income deciles between 1993 and 2015. As explained in Section 3, our methodology differs by focusing on the share of total household expenditure after equivalisation and the deduction of housing costs devoted to energy purchases for the home. We believe the latter approach provides more precise comparisons of affordability pressures across households.

Waddams and Deller (2015) and Deller (2016) take a different approach from the current paper, by comparing affordability across several EU states and assessing the ability of policy interventions to alter FP rates. As noted above in Section 1, Deller and Waddams Price (2018) is a companion to the present paper, using the same corrected ENEX dataset to compare FP rates based on ENEX reported by households (the present dataset) and the official FP statistics based on 'required' (modelled) ENEX. ${ }^{10}$ Deller and Waddams Price (2018) note that failing to correct for the PPM measurement issue may have led earlier studies ${ }^{11}$ to find erroneously that average reported ENEX lay noticeably below average required ENEX.

A further group of papers investigates the determinants of UK households' ENEX econometrically. An early example is Baker et al (1989), while Baker and Blundell (1991) estimate price and income elasticities for gas and electricity by season, central heating fuel and tenure. Crawford et al. (1993) explicitly look at the distribution of ENEXShr by income. Other papers utilise data from the British Household Panel Survey (BHPS); for example, Meier and Rehdanz (2010) consider determinants of ENEX for renters and home owners, while Meier et al. (2013) further investigate the relationship between income and ENEX. The present paper complements these more focused studies by charting the long-term trends in ENEX and ENEXShr against the policymaking context.

\section{Data and Methodology}

The data come from the Living Costs and Food Survey and its precursors, the Expenditure and Food Survey and the Family Expenditure Survey. These are annual cross-sectional surveys designed to be nationally representative, where each household has their expenditure data collected over a short period at one point in the year. The data are used to form an annual time series from 1992 to 2014, with additional observations in 1977, 1982 and 1987. The surveys' sample sizes vary between 4,900 and 7,500 households. Weights are applied to ensure representativeness. ${ }^{12}$

\footnotetext{
${ }^{9}$ Specifically Figure 3.2, pg 59.

${ }^{10}$ The official FP statistics calculate required ENEX from a set of assumed behaviours and an engineering model utilising a dwelling's physical characteristics to estimate the ENEX required to maintain a specified target temperature.

${ }^{11}$ Hirsch et al (2011) and DECC (2014).

12 Official survey weights are used when available. Prior to 2001-02 weights have been calculated using a simplified version of the official methodology which compares the survey sample with census data. The simplified weights utilise the household head's age and gender along with the household's region/devolved administration. The weights between 1992 and 2000-01 use the 1991 census, while earlier years use the 1981 census.
} 
ENEX figures are annualised and defined as the total expenditure reported by household members on all fuels to provide fuel, light and power to their home ${ }^{13}$ (i.e. excluding transport expenditure). ENEX is converted to 2014 prices using the Retail Price Index (RPI) ${ }^{14}$.

ENEXShr is calculated as a proportion of total household expenditure. Total expenditure is used, rather than income, since it displays less volatility and provides a better indication of living standards. ${ }^{15}$ As this paper aims to identify affordability pressures, total expenditure is calculated after-housing-costs have been deducted and is equivalised using the modified OECD scale ${ }^{16}$. If housing costs were not deducted, total expenditure of those paying rent or mortgages would be inflated relative to those owning their homes outright. ${ }^{17}$

Before analysing ENEXShr two corrections are applied. Sections 3.1 and 3.2 describe the evidence supporting our correction of PPM ENEX, and the methodology applied. Section 3.3 describes how ENEX has been de-seasonalised for each of the three payment methods (Direct Debit, Arrears, PPM) ${ }^{18}$.

\subsection{Evidence for our correction of PPM expenditures}

While Advani et al. (2013) have corrected the ENEX reported by PPM users by assuming that many consumers topped up their PPMs less frequently than fortnightly, we have implemented a different assumption and correction, based partly on evidence from more recent LCF data. Our decision to treat PPM 'zeros' as missing data is based on several pieces of evidence.

First, there is a sharp jump in median ENEX for PPM households between 2012 and 2013, coinciding with a change in the questions posed in the LCF. Prior to 2013, PPM ENEX was collected in a two week 'expenditure diary' where households were asked to record expenditures as they occurred. If a PPM user did not top-up within the two week diary window, their PPM ENEX was recorded as zero, so their annualised PPM ENEX was also recorded as zero. In contrast, if a consumer paid by Arrears or Direct Debit, they were asked to state the amount of their last energy bill and the period to which it referred.

The percentage of PPM zero observations increased significantly during the $1990 \mathrm{~s}^{19}$, coinciding with a substantial decrease in PPM consumers' median ENEX ${ }^{20}$. However from 2013 PPM consumers were asked a two-part question mirroring that for Direct Debit and Arrears customers; the first question asked "How much did you last put on your key/meter?", while the second question asked "How long

\footnotetext{
${ }^{13}$ ENEX related to second homes is included.

${ }^{14}$ ENEXShr, as a fraction, is independent of the choice of inflation measure, however, the choice of CPI or RPI will affect time variations in real ENEX. Since CPI is generally lower than RPI, using CPI would make ENEX in earlier years fall relative to the results in this paper.

${ }^{15}$ For example, see Brewer and O'Dea (2012).

${ }^{16}$ See http://www.oecd.org/eco/growth/OECD-Note-EquivalenceScales.pdf

${ }^{17}$ Equivalisation and the deduction of housing costs mean reported ENEXShr are larger than the simple proportion of household expenditure devoted to energy. Equivalisation and deducting housing costs increases median ENEXShr in 2014 from 5.3\% to 10.6\%. Figure A2.1 reports the distribution of unequivalised ENEXShr inclusive of housing costs.

${ }^{18}$ Direct Debit involves money taken from a customer's bank automatically every month or quarter; Arrears (Standard Credit) involves customers receiving a bill asking for payment covering the previous quarter's consumption; and PPM requires consumers to pay for energy before use.

${ }^{19}$ We do not have an explanation for this increase, however, during the 1990s, the percentage of households with PPMs increased, PPMs were increasingly used for debt management and PPM technology switched from inserting tokens/coins into a PPM to electronic top ups.

${ }^{20}$ See Figure A2.2.
} 
would this amount normally last at this time of year?"21. When this question change was introduced, 'zero' PPM observations virtually disappeared; and median estimated ENEXfor electricity PPM users more than doubled, from $£ 613$ to $£ 1295$ between 2012 and 2013.

Second, Figure 1 shows that the sharp increase in median ENEX for PPM consumers between 2012 and 2013 in the raw data (111\%) is neither replicated for other payment methods (3.6 and 3.0\% increases) nor in PPM pricing data, i.e. it is specific to the LCF's PPM data. ${ }^{22}$

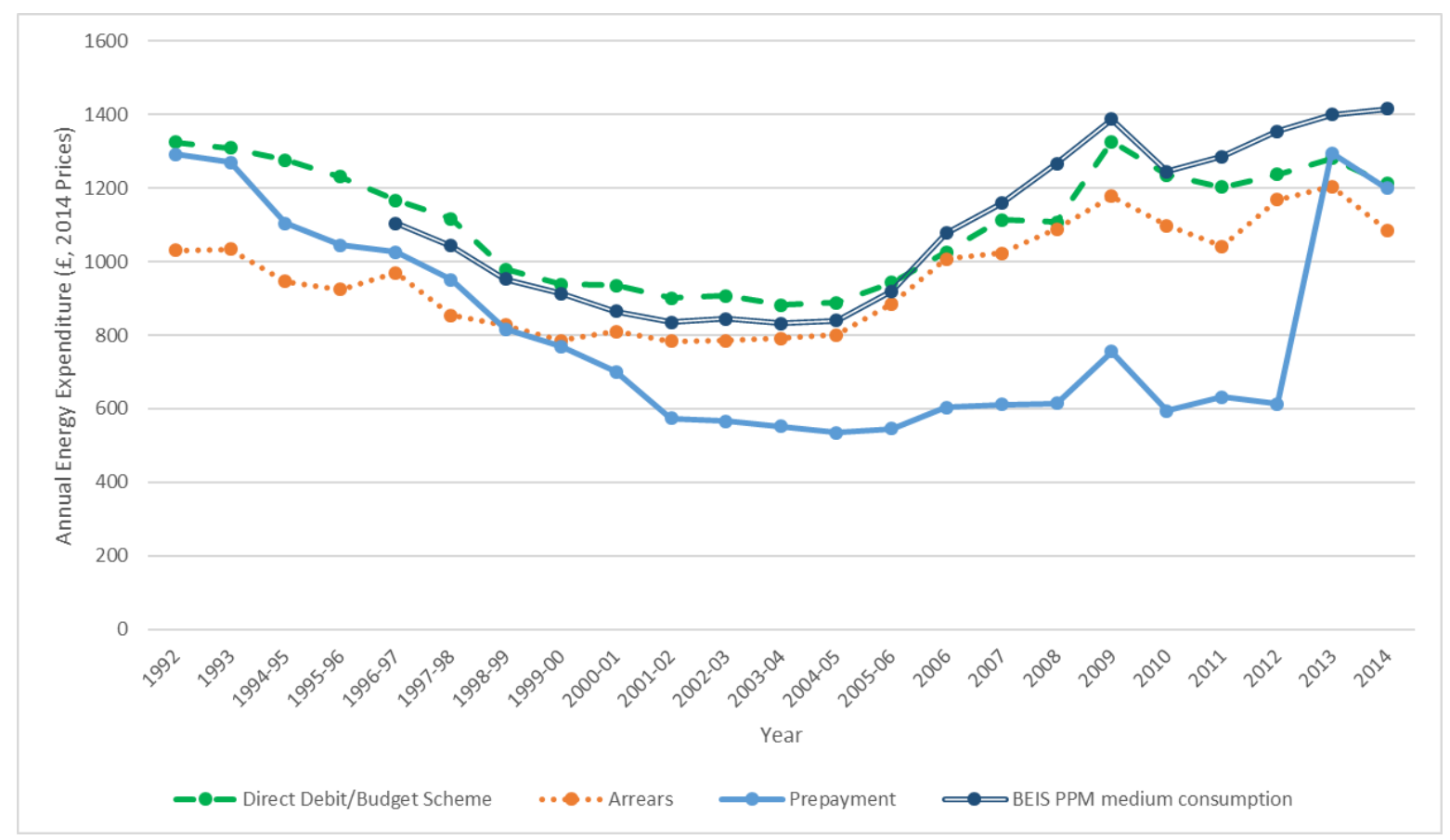

Figure 1 - Median ENEX (raw data) by electricity payment method and BEIS Medium Consumption PPM bill23

Third, survey evidence from Waddams et al. (2001) shows that almost three quarters of electricity PPM households charged their cards weekly, contradicting Advani et al.'s assumption that many PPM consumers top-up less frequently than once a fortnight. This pattern seems fairly consistent, since Mummery and Reilly (2010) use more recent data to find "Two-thirds of PPM households topped up their meter at least once in a typical week" ${ }^{24}$.

A related point is 'self-disconnection', i.e. when PPM users have run out of credit on their PPM and do not top up in order to economise. The survey evidence suggests that this phenomenon is unlikely to explain the PPM data issue, since self-disconnection is relatively rare and typically lasts for short

\footnotetext{
${ }^{21}$ See pg 142, 'Living Costs and Food Survey - Volume B: The Household Questionnaire User Guide, January December 2013', ONS Social Surveys, Office for National Statistics, November 2014, http://doc.ukdataservice.ac.uk/doc/7702/mrdoc/pdf/7702_volume_b_household_questionnaire_2013.pdf 22 'BEIS PPM medium consumption' in Figure 1, the energy bill resulting from fixed consumption and PPM tariffs sampled from energy firms, shows an increase of only 3.3\% between 2012 and 2013. 'BEIS PPM medium consumption' involves summing the relevant columns of Table 2.2.1 and Table 2.3.1, 'Annual domestic energy bills', Department of Business, Energy and Industrial Strategy available at:

https://www.gov.uk/government/statistical-data-sets/annual-domestic-energy-price-statistics . Electricity expenditure involves consumption of $3,800 \mathrm{kWh} /$ year. Gas expenditure involves consumption of $15,000 \mathrm{kWh} /$ year.

${ }^{23} 1997-98$ and 2002-03 etc. refer to financial years (April to April).

${ }^{24}$ See pg 14
} 
periods. Waddams et al (2001) report that $24 \%$ of electricity and $27 \%$ of gas PPM users had selfdisconnected in the previous year, of whom $42 \%$ (28\% for gas) had done so only once. Mummery and Reilly (2010) report that only $16 \%$ of PPM households had self-disconnected in the previous year and half of this group did so only once or twice. Further, Mummery and Reilly note that self-disconnection generally lasted only hours: only $9 \%$ of those self-disconnecting typically did so for more than 24 hours and only $1 \%$ disconnected for two days or more ${ }^{25}$.

Third, we observe limited seasonality in the percentage of PPM observations that are zero. If zero expenditures were due to infrequent top-ups, we would expect many fewer top-ups (and a greater proportion of zeros) in summer months. Figure 2 does shows some seasonality, particularly for gas PPMs between May and August, when infrequent top-ups would be most likely due to limited heating demand. However the proportion of 'seasonal' zeros relative to all zeros appears small: even in winter around $45 \%$ of PPM consumers report zero electricity (gas) expenditure.

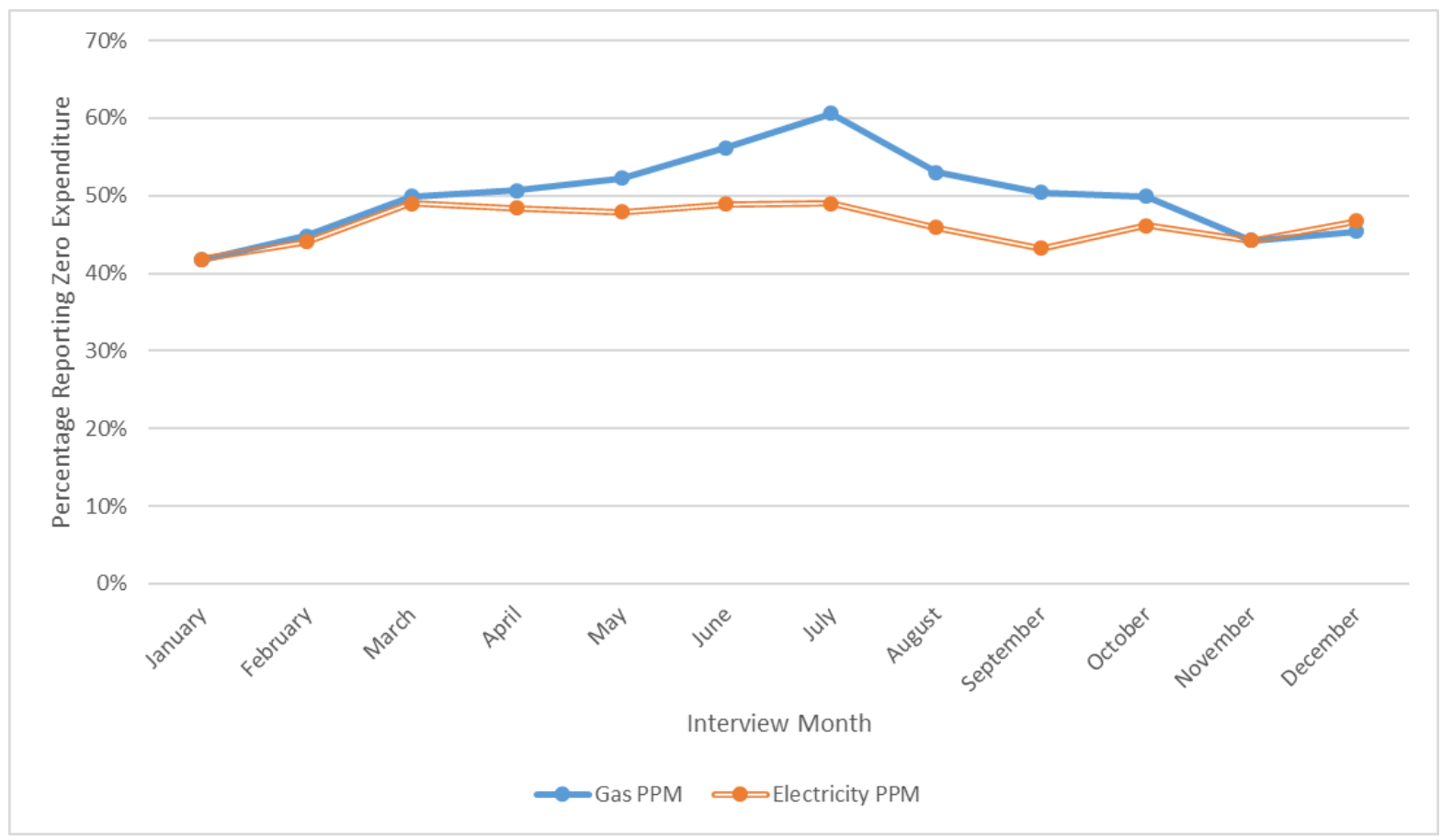

Figure 2 - Percentage of PPM users reporting 'zero' expenditure for relevant fuel by interview month, averaged over 2001-02 to $2012^{26}$

Fourth, after we perform the PPM correction in Section 3.2 to the data prior to 2013, the time trend of the corrected PPM ENEX data moves much closer to that of Direct Debit and Arrears ENEX (Figure 3). Rather than doubling between 2012 and 2013 (when the question change occurred) median corrected PPM ENEX increases by only $8.3 \%$, compared with $4.2 \%$ for Arrears and $3.4 \%$ for Direct Debit.

\footnotetext{
${ }^{25}$ Vyas (2014) report results broadly consistent with Mummery and Reilly.

${ }^{26}$ This covers the years when the highest rates of zeros were recorded (see Figure A2.2).
} 


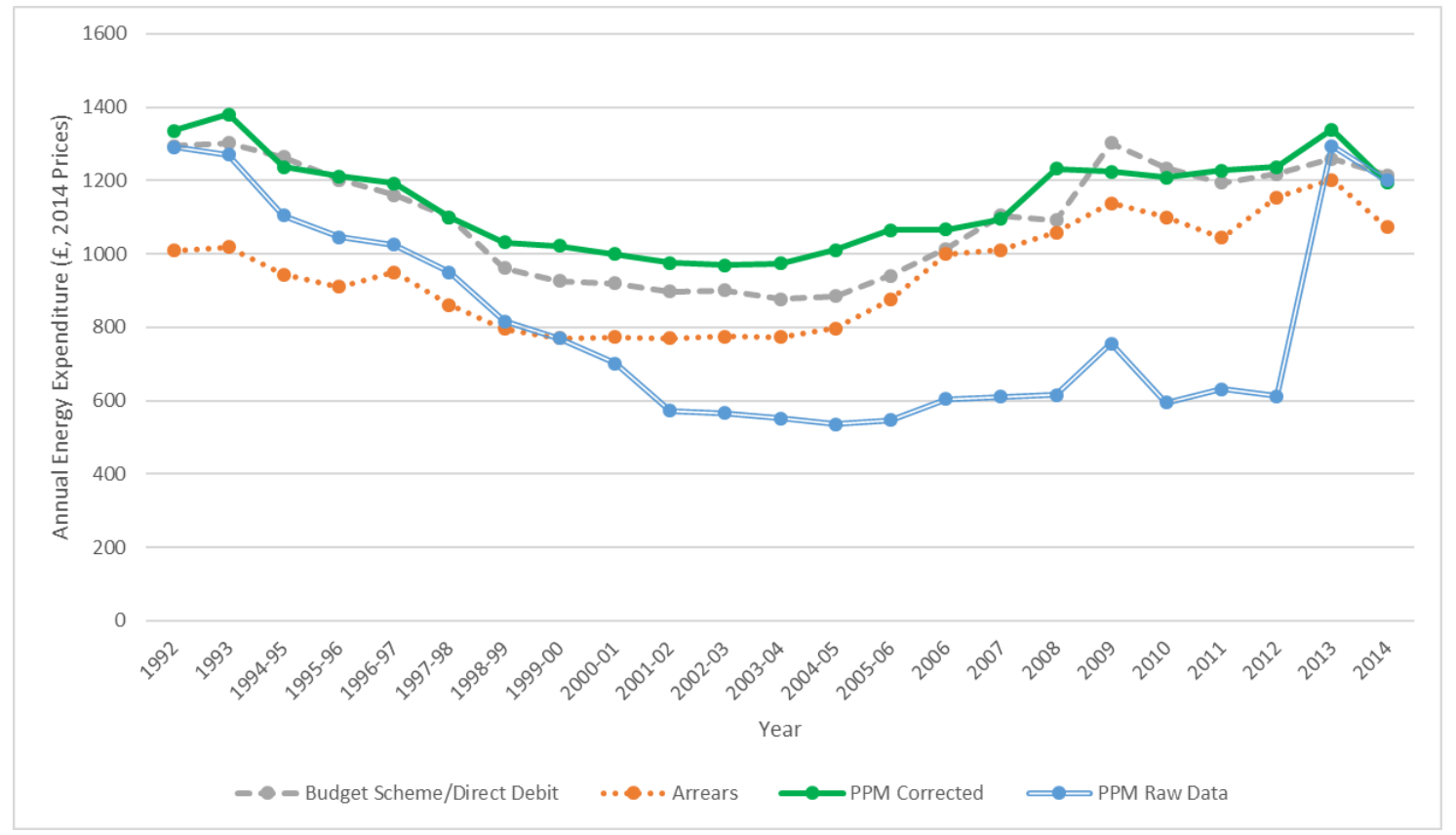

Figure 3 - Median annual ENEX by electricity payment method

\subsection{Methodology for imputing missing PPM ENEX}

Separate OLS regressions for gas and electricity are run in each year ${ }^{27}$ taking the form:

$$
y_{i}=x_{i}^{\prime} \beta+\varepsilon_{i}
$$

where the dependent variable, $y_{i}$, is expenditure on electricity (gas), $x_{i}$ are the explanatory variables, $\beta$ are the coefficients to be estimated and $\varepsilon_{i}$ is the error term. $\beta$ is estimated using data from those PPM users who record positive expenditure on the relevant fuel in the relevant year. $A$ comprehensive range of household characteristics are included in $x_{i}$ : region/devolved administration, household composition, gender of household head, equivalised after-housing-costs income decile, age of household head, employment status of household head, number of cars owned, type of dwelling, tenure type, number of rooms in the dwelling, central heating fuel, interview month, whether there is an internet connection and whether certain household appliances are owned (tumble dryer, microwave, dishwasher, TV). $\beta$ is combined with the values of $x_{i}$ for the households reporting zero PPM electricity (gas) expenditure to estimate their PPM electricity (gas) expenditure.

Our correction differs from Advani et al. (2013) who assumed that average PPM expenditures in the raw data were correct and that excessive zeros simply affected the dispersion of the ENEX distribution. Advani et al. (2013) focus on correcting this excessive dispersion; their assumption of infrequent top ups implies not only that some households report zero electricity (gas) expenditure in the two week diary window, but that positive ENEX recorded in the two week diary window will generally be 'too high', in the sense that it covers a period longer than two weeks. In contrast, our correction treats positive PPM expenditure observations as correct values and estimates the expenditure for households reporting zero expenditure.

Given the seasonal variation in reports of zero gas expenditures shown in Figure 2, we recognise that some of the zeros observed in the survey data are likely to be 'real' in the sense that they result from

\footnotetext{
${ }^{27}$ No PPM correction is applied in 1977, 1982 and 1987 due to the low percentage of 'zero' observations, see Figure A.3 of Advani et al (2013).
} 
infrequent top-ups. Since we replace these 'real' zeros with estimates of positive expenditure, and leave top ups that might last longer than two weeks unaltered, we are, strictly speaking, estimating upper bounds for average ENEX and ENEXShr. However the limited degree of seasonality in Figure 2 implies that these upper bounds are reasonably close to the true values of average ENEX and ENEXShr.

\subsection{Seasonal Adjustment}

If seasonality corrections were not applied, the probability of a household lying in the upper or lower tail of the ENEX/ENEXShr distribution could depend on the month of interview. ${ }^{28}$. We use similar seasonality corrections to those of Advani et al. (2013), running separate OLS regressions for Direct Debit, Arrears and PPM for each fuel (electricity and gas) ${ }^{29}$ in each year ${ }^{30}$. The OLS regressions take the log-linear form:

$$
L N y_{i}=x_{i}^{\prime} \beta+\varepsilon_{i}
$$

where $y_{i}, x_{i}$ and $\varepsilon_{i}$ are as in equation (1) above. To enable de-seasonalisation, interview month dummies are included in $x_{i}$. Using the co-efficients of the month dummies, electricity (gas) expenditure can be estimated for each household for the 11 months when it was not interviewed. A simple average is then calculated of the twelve electricity (gas) expenditure figures to produce a deseasonalised estimate for annual electricity (gas) expenditure. Total ENEX for each household is the sum of the estimates for electricity expenditure, gas expenditure (where relevant) and any expenditure on other fuels.

In addition to charting ENEX and ENEXShr, three statistical tests have been performed on key relationships in selected years: (i) a non-parametric equality of medians test; (ii) the Wilcoxon ranksum test/Mann-Whitney two-sample statistic; and (iii) a quantile (median) regression with a single explanatory variable representing the different groups/years being compared ${ }^{31}$. Unless otherwise stated, the level of statistical significance stated in the text holds for all three statistical tests.

\section{Energy Expenditures and Energy Expenditure Shares}

We first examine the time trends of median ENEX and ENEXShr. Since the most costly affordability support policy, WFP, is targeted at older households, we then explore how ENEX varies by household income and age of household head. ENEX and ENEXShr breakdowns by tenure, household composition and UK nation are provided in Appendix 1. The broad trend across household groups is that elevated median ENEXShr for certain household is driven more by lower total expenditure (income) than higher ENEX.

\footnotetext{
${ }^{28}$ If there is any correlation between household characteristics and interview month, this could create problems for our analysis broken down by different household characteristics.

${ }^{29}$ Due to the small number of observations, no corrections are applied to ENEX involving other fuels or other payment methods.

${ }^{30}$ For PPM users the seasonality regressions are only run using those households reporting non-zero electricity (gas) expenditures. However, the de-seasonalisation process is applied to all PPM households, including those whose electricity (gas) expenditure was estimated using the methodology in Section 3.2.

${ }^{31}$ As the PPM imputation in Section 3.2 artificially restricts the sample variance compared to the true PPM ENEX distribution (the imputed PPM values exclude 'randomness'), the statistical tests in years prior to 2013 may overstate the statistical significance of differences. However, the severity of this issue should be limited, since in any given year no more than $9.6 \%$ of households require imputation.
} 


\subsection{Median ENEX and ENEXShr through time}

Figure 4 shows the evolution of ENEX in real and nominal terms between 1992 and 2014, relative to its level in $1992^{32}$. In real terms median ENEX between 1998-99 and 2005-06 was around 20\% below its 1992 level, while since 2009 real median ENEX has been around 10\% above its 1992 level. Real median ENEX in 2003-04 is significantly different (at the 1\% level) from its values both in 1992 and 2014.

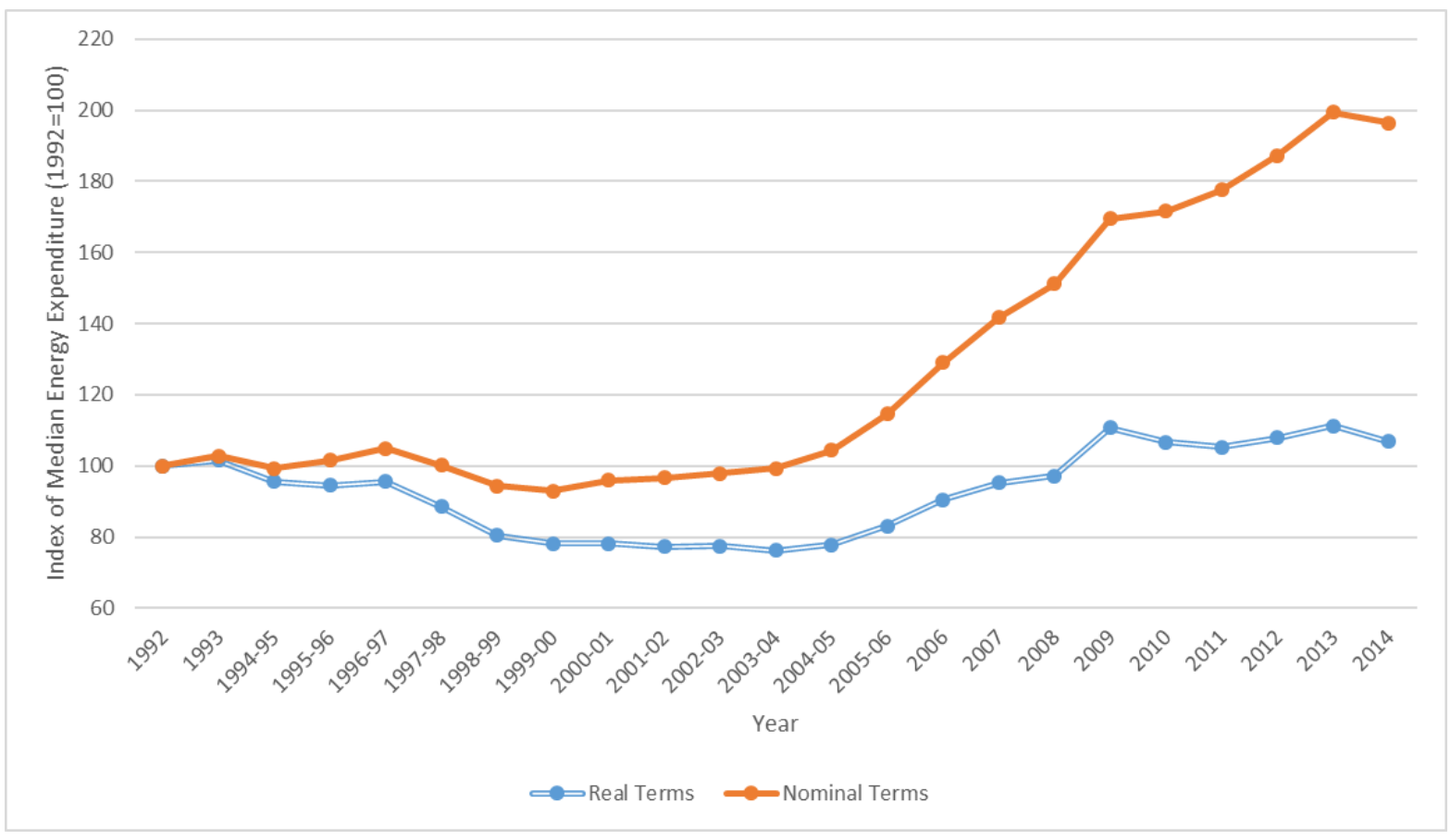

Figure 4 - Indices of median ENEX in nominal and real terms, 1992-2014 (1992 = 100)

However the picture of nominal ENEX is rather different and explains the political attention given to the cost of energy over the past decade, particularly if consumers focus on year-to-year comparisons of their bills. ENEX in nominal terms doubled between 2003-04 and 2013, supporting adages such as 'energy bills only ever go up'. While inflation is the norm, this rising nominal ENEX is striking for two reasons. First, increasing nominal ENEX has occurred at the same time as average household energy consumption has fallen, by around a quarter since 2004 (see Figure A2.4). Second, the surprising stability of nominal ENEX in the decade preceding 2003-04 may have further increased the salience of bill increases after this point. Both of these factors may have furthered consumers' sense of grievance regarding the energy market.

Additionally, the timing of the increases in ENEX/ENEXShr plays to political and ideological divisions around the merits of liberalised markets. While increases in ENEX/ENEXShr after 2003-04 are associated with rising wholesale energy prices, the timing provides ammunition to those who critique liberalisation, since these increases began shortly after the final removal of retail price controls in 2002.

To gauge the changing pressure on household budgets from ENEX, Figure 5 reports an index of median ENEXShr through time (1992=100). Between 1992 and 2002-03 median ENEXShr fell by 36\% while most of the subsequent increase occurred between 2004 and 2009, with median ENEXShr then

${ }^{32}$ Figures A2.3 summarises the ENEX distribution in constant (2014) prices. 
hovering around its 1992 level. Median ENEXShr reached a low of 6.7\% in 2002-03 and 2003-04, compared with $10.6 \%$ in $2014,10.6 \%$ in 1992 and $12.3 \%$ in $1982^{33}$. These comparisons demonstrate that while ENEXShr after 2009 appears high in a 10-year perspective, ENEXShr in 2013 is similar to its level in the late 1980s and early 1990s, and lower than in the early 1980s. In this longer-term view, the low ENEXShr and relative affordability of energy in the early 2000s appears more exceptional than the recent high values. However householders rarely consider 20+ year time horizons, and so the pressures facing policymakers around the retail energy market are likely generated by the shorter term ENEXShr increases.

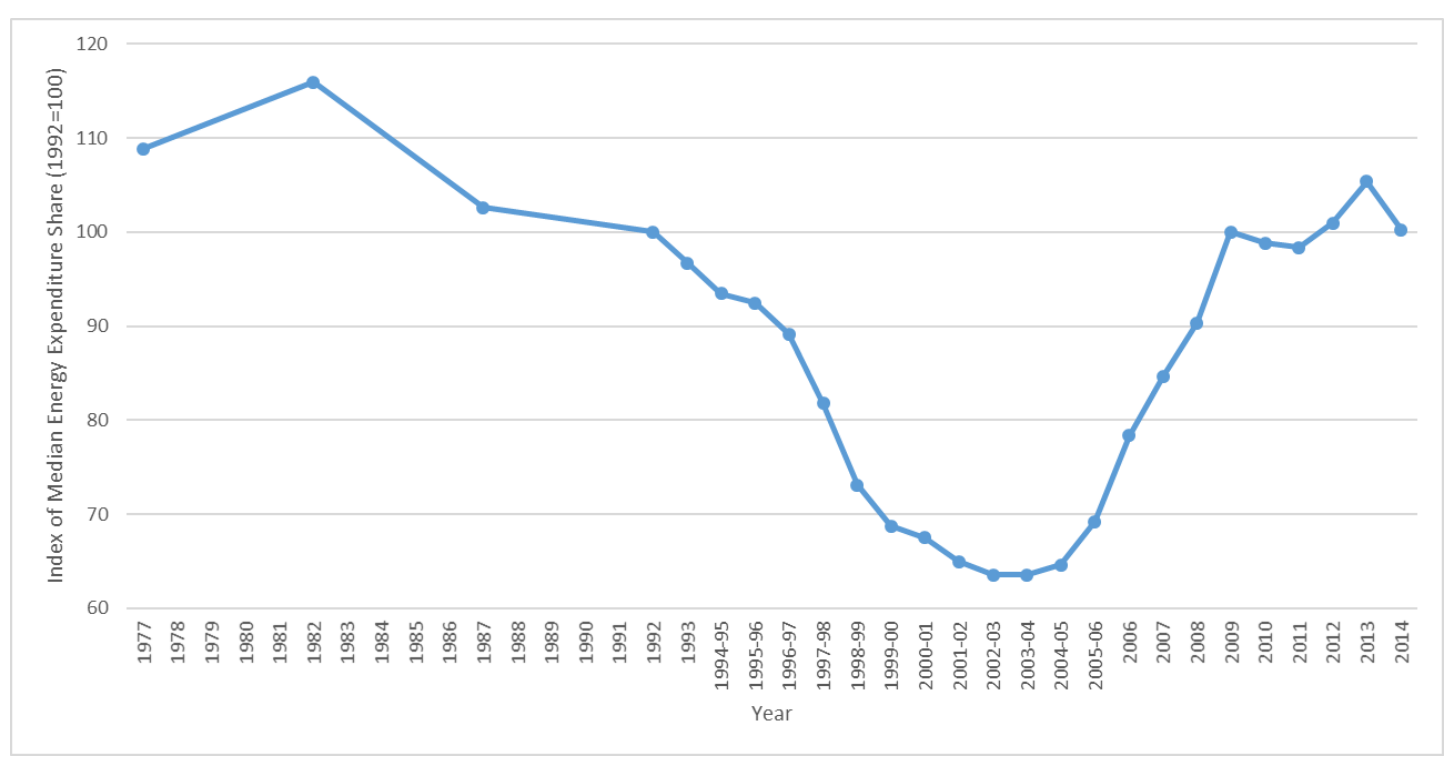

Figure 5 - Index of median (equivalised after-housing-costs) ENEXShr, 1992-2014

\footnotetext{
${ }^{33}$ Figure A2.5 reports the full ENEXShr distribution through time. Median ENEXShr in 2003-4 is significantly different (at the 1\% level) from its values in 1992 and 2014.
} 


\subsection{ENEXShr variations by income decile and age of household head}

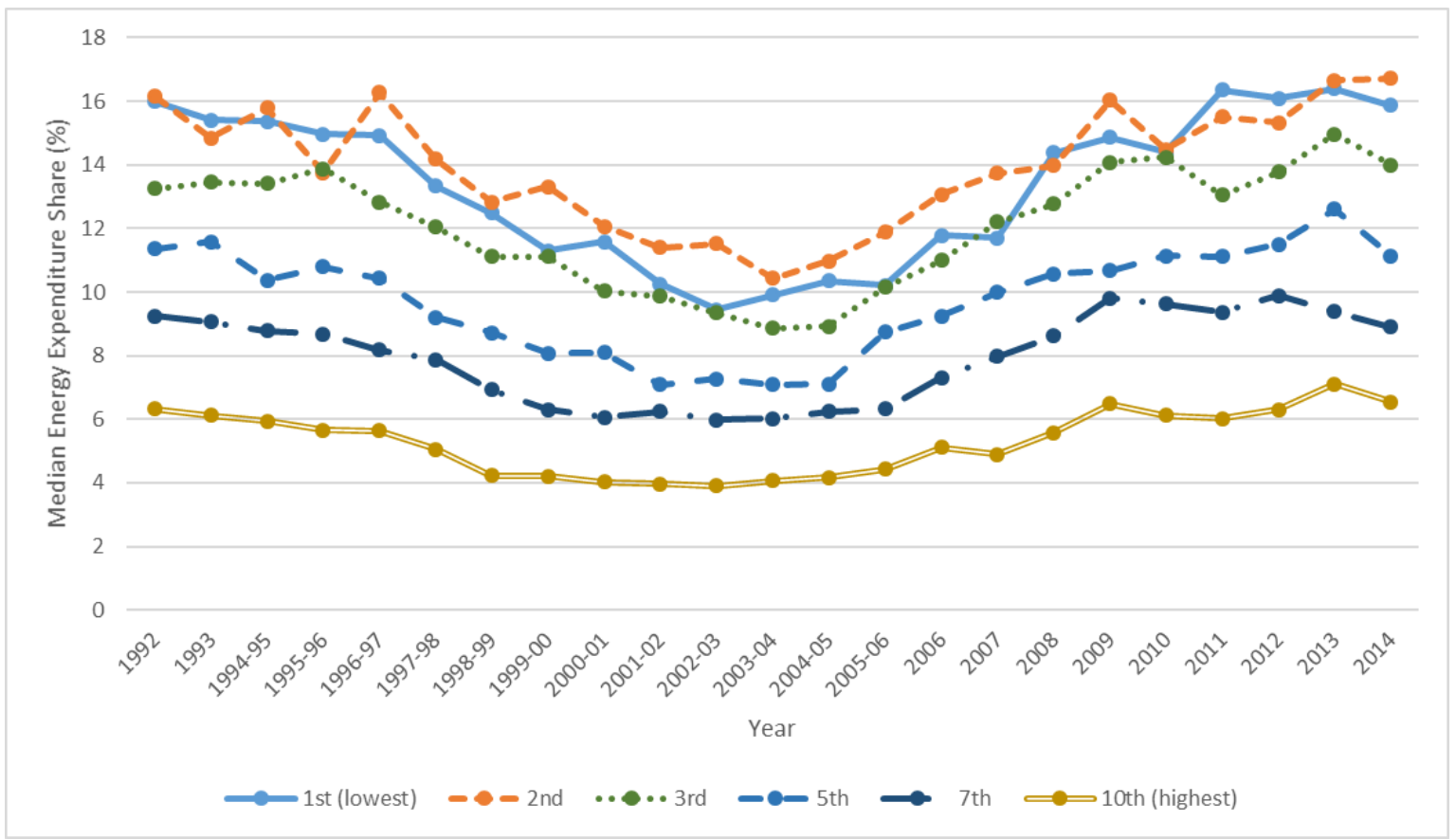

Figure 6 - Median (equivalised after-housing-costs) ENEXShr by equivalised after-housing-costs income deciles, 1992-2014

Figure 6 illustrates the higher ENEXShr of households in the lower income deciles ${ }^{34}$ : the median ENEXShr of the lowest income decile in 2014 was $15.8 \%$, almost two and a half times the ENEXShr of the highest decile (6.6\%). This difference indicates the much greater salience of ENEX, and ENEX increases, for low income households.

Moreover this divergence of median ENEXShr across income deciles increases at higher levels of ENEXShr, as at the beginning and end of the time period shown in Figure 6 . The 6.0 percentage point increase in median ENEXShr between 2003-04 and 2014 for households in the bottom income decile represents a more acute relative welfare reduction than the corresponding 2.5 percentage point increase in median ENEXShr for the top income decile.

Comparing the income-ENEXShr relationship across different regulated sectors provides further insight into why the retail energy market has attracted political attention. Figure 7 charts the share of household expenditure devoted to energy, water, telecoms and transport ${ }^{35}$ by equivalised afterhousing-costs income decile in 2014. First, for all income deciles, the share of expenditure devoted to household energy exceeds that for telecoms and water by a noticeable amount. Second, this gap is particularly large for the bottom three income deciles. Third, for these bottom three income deciles

34 The lowest income decile has a central estimate of median ENEXShr below that of the second income decile between 1996-97 and 2007. In six years between these two dates the equivalence of the two decile's median ENEXShr can be rejected at at least the $5 \%$ level. This finding appears to result from applying equivalisation and deducting housing costs from income when determining the income deciles. In 14 years between 1992 and 2014 the equivalence of median ENEXShr in the first and second income deciles could not be rejected.

${ }^{35}$ Only ENEX is deseasonalised. Water expenditure includes both water and sewerage; water expenditures that are part of rental payments or property service charges are not included. Telecoms expenditure covers fixed telephony, mobile telephony and broadband, but excludes pay TV services. Transport expenditure covers both private and public transport but excludes vehicle purchase costs. 
the proportion of expenditure devoted to household energy also exceeds that for transport by a noticeable margin. Thus the salience of rising home energy costs to households facing budgetary challenges is likely to be greater than for price increases in these other regulated sectors.

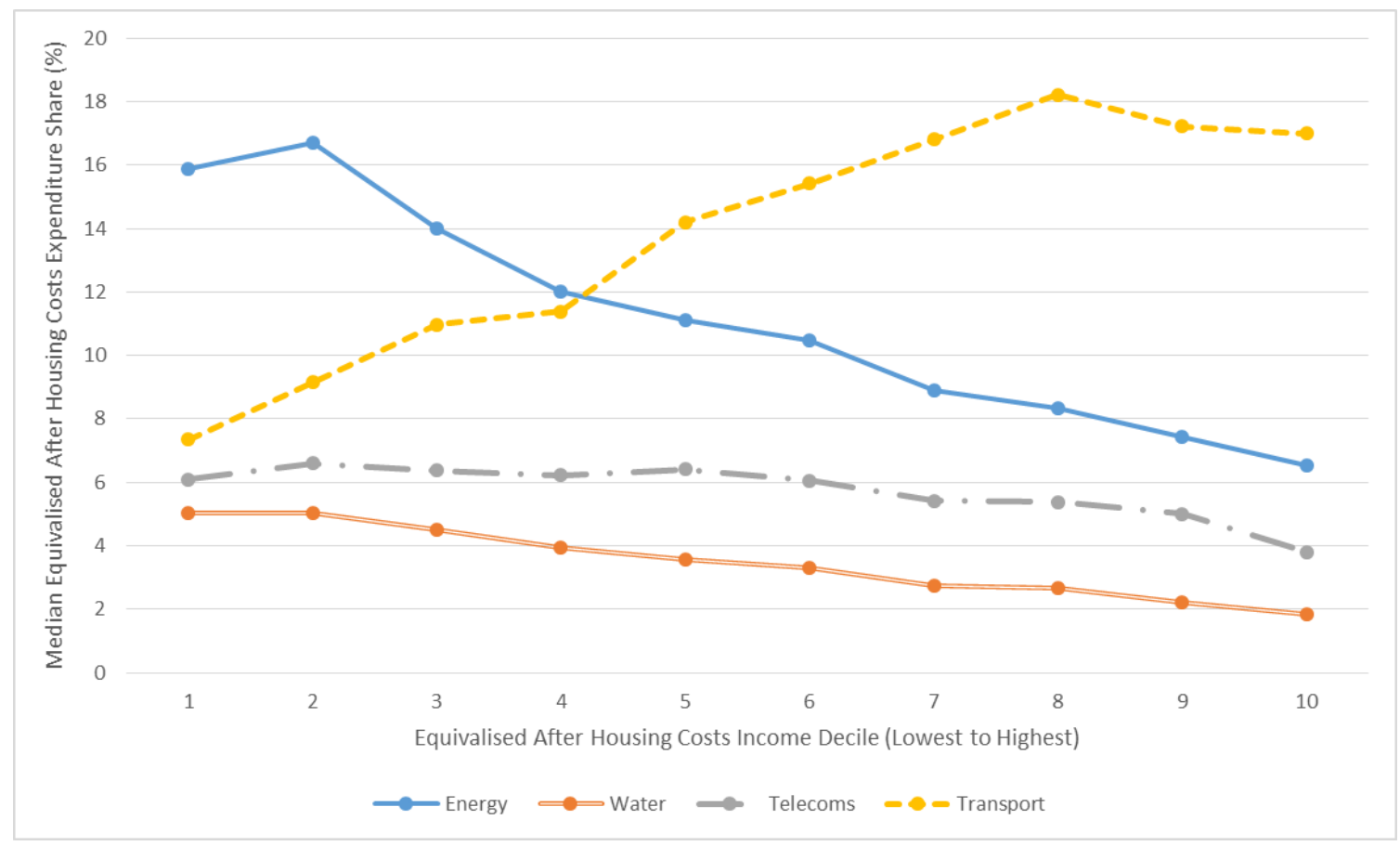

Figure 7 - Median share of (equivalised after-housing-costs) household expenditure devoted to different regulated sectors by equivalised after-housing-costs income decile, 2014

ENEXShr among older households carries particular significance since the UK's costliest energy affordability related benefit, the Winter Fuel Payment ${ }^{36}$, is available to individuals who are older than the female state pension age ${ }^{37}$. As discussed in Section 5.2, the choice to target resources at older households rather than those on low incomes is potentially notable. Figure 8 shows that while households with a head aged over 80 have an ENEXShr similar to households in the the lowest three deciles of the equivalised after-housing-costs income distribution, households with a head aged 6570 display ENEXShr similar to households in the fifth income decile ${ }^{38}$. This suggests that affordability pressures alone ${ }^{39}$ offer a weak justification for providing households aged 65-70 with financial support

\footnotetext{
${ }^{36}$ WFP is a social benefit which increases income rather than reduces ENEX. While WFP is equivalent to a large proportion of households' median ENEX (see Section 6), its recording as income limits its impact on ENEXShr.

37 See https://www.gov.uk/winter-fuel-payment/eligibility.

${ }^{38}$ In all years, it is possible to reject the equivalence of the median ENEXShr between the third and fifth income deciles at the $1 \%$ level and to reject the equivalence of the median ENEXShr between households with a head aged $65-70$ and those with heads aged $80+$ at the $1 \%$ level. The time series in Figure 8 are inclusive of any impact on ENEXShr from the different policy interventions detailed in section 5. Significantly the finding of 6570 year old households having similar ENEXShr to the middle of the income distribution precedes the substantial increase in affordability support to this age group which began in 1997-98. Also, a basic robustness check (where the value of WHD is added to the ENEX and total expenditure of all households with a head over the age of 65 in 2011-2014) still shows those aged 65-70 having ENEXShr around the middle of the income distribution.

39 If the consequences, for example to health, of restricting energy consumption are greater for older households there may still be a justification taking measures to ensure older households can easily afford energy.
} 
with their energy bills, when compared to the policy option of expanding support to a wider set of low income households.

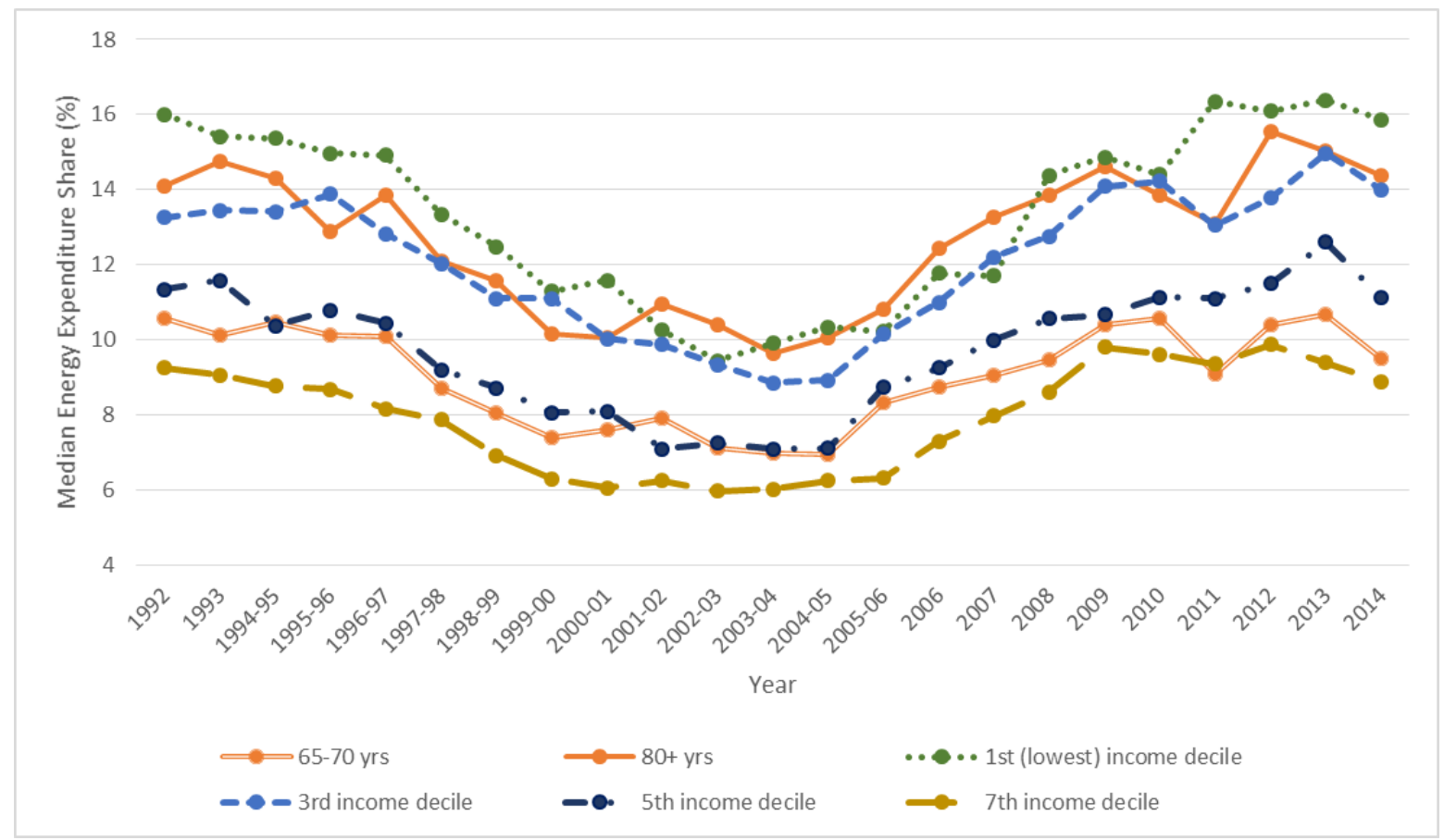

Figure 8 - A comparison of (equivalised after-housing-costs) ENEXShr for selected age groups and income deciles, 1992-2014

The analysis in this section focuses on ENEXShr by income decile and age of household head, since successive governments have directed energy affordability support policies at older households rather than low income households. In Appendix 1 ENEXShr and ENEX variations across a range of household characteristics (tenure, household composition and devolved administration) are mapped. Looking across these mappings,groups with elevated median ENEXShr tend to have low total household expenditure ${ }^{40}$ (income) rather than elevated ENEX ${ }^{41}$. This raises the policy question of whether it is generally useful to view differences in energy affordability challenges across household groups as being an energy-specific problem, to address within the energy sector, rather than a striking symptom of low incomes.

\section{Affordability Support Policies}

The ENEXShr time series provides context to energy affordability policies in England ${ }^{42}$. In this section we explore the timing of policies and benefits targeted at improving energy affordability alongside of the evolution of ENEXShr over time. Both the first FPS and WFP were introduced when ENEXShr was approaching historic lows, rather than being responses to high and/or rising ENEXShr.. These policies seem to have been influenced as much by government ideology, the electoral cycle and fiscal constraints following the Financial Crisis, as by energy affordability concerns.

\footnotetext{
${ }^{40}$ After equivalisation and the deduction of housing costs.

${ }^{41}$ The main exception is in Northern Ireland, which experiences both elevated ENEX and ENEXShr, likely due to its limited gas grid.

${ }^{42}$ We focus on England as FP policies are the responsibility of the devolved administrations.
} 
The following discussion focuses on FPS as an indicator of the importance given to alleviating energy affordability issues ${ }^{43}$ and on WFP because of its high cost and the distributional consequences of its targeting.

\subsection{The Fuel Poverty Strategy (FPS)}

The FPS is clearly not a response to increasing affordability pressures, since the first FPS was introduced in 2001, as median ENEXShr was falling towards a long-term low (see Figure 9).

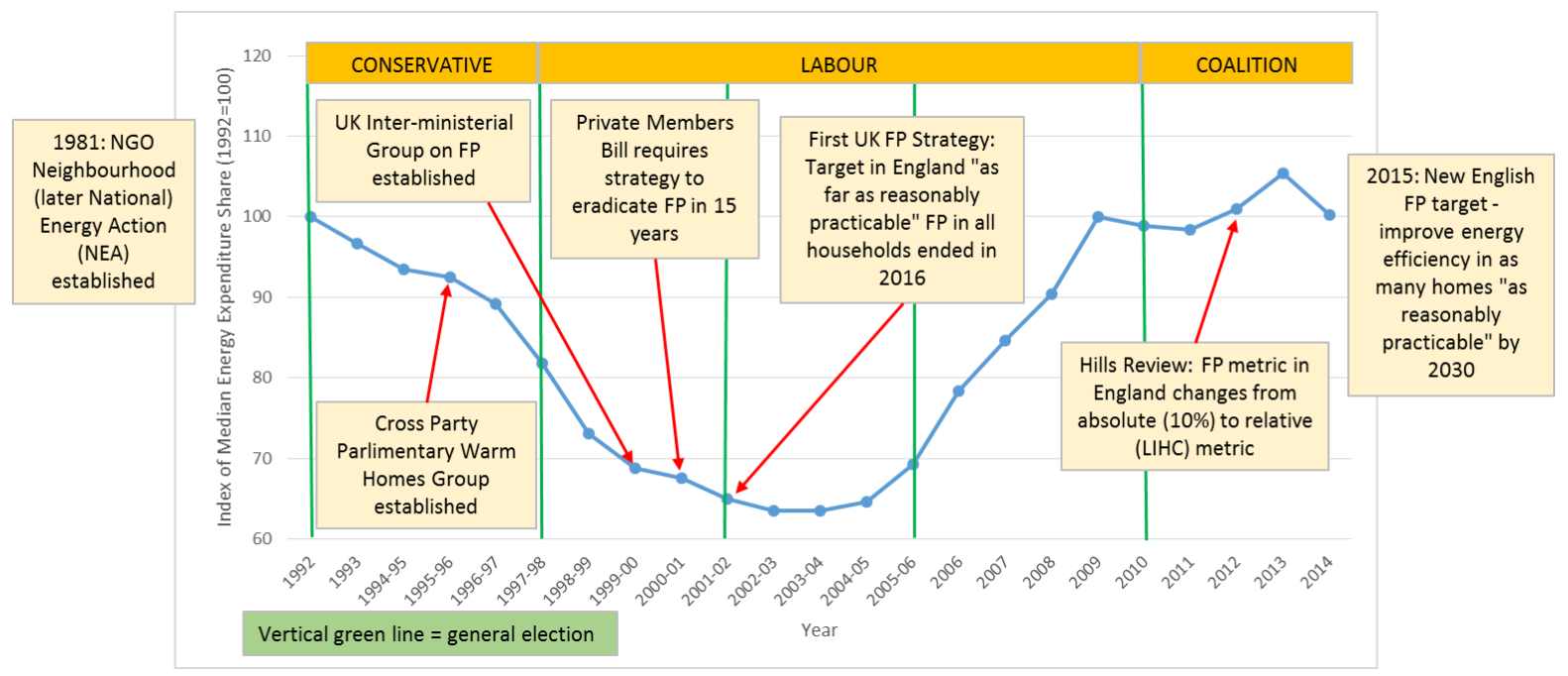

Figure 9 - FPS developments and an index of median (equivalised after-housing-costs) ENEXShr

However the first steps towards FP being an issue for policy intervention had been taken during the higher affordability pressures of the late 1970s and early 1980s. Isherwood and Hancock (1979) suggested the concept, and in 1981 the NGO Neighbourhood (later National) Energy Action was founded. Boardman's book (1991) stimulated growing political awareness of FP, even as median ENEXShr were falling. While reducing FP is mentioned in Labour's 2001 election manifesto ${ }^{44}$, the FPS was a response to an earlier Private Members Bill by the Conservative MP David Amess (see Kidson and Norris, undated). Following strong support in Parliament, the Warm Homes and Energy Conservation Act was passed in 2000.

Figure 9 also illustrates the increasing challenge of reducing FP as ENEXShr rose after 2003-04, potentially explaining a softening of the target contained in the FPS. The Labour government's 2001 FPS sought an end to fuel poverty for vulnerable households by 2010, "with a target that by 22 November 2016 no person in England should have to live in fuel poverty" 45 , although, both ambitions were subject to the proviso "as far as reasonably practicable". Until 2012 a household was defined as FP if ENEX exceeded $10 \%$ of household income; this specification of a fixed threshold rendered the FP rate sensitive to energy price fluctuations. Figure 10 shows that as ENEX rose between 2003-04 and

\footnotetext{
${ }^{43}$ We do not explore specific energy efficiency policies due to: (i) their complexity; (ii) uncertainty regarding whether their main objective was to reduce energy bills or carbon emissions; and (iii) uncertainty in their timing and impact on energy bills. Including supplier obligations, Advani et al (2013) record 11 major energy efficiency schemes between 1994 and 2013.

44 "Fuel poverty blights lives: our aim is that by 2010 no vulnerable household in the UK need risk ill-health due to a cold home", pg 13, 'Ambitions for Britain - Labour's manifesto 2001', available at: http://www.politicsresources.net/area/uk/e01/man/lab/ENG1.pdf ${ }^{45}$ See pg 7, DEFRA (2004).
} 
2009 the official FP rate rose from $5.9 \%$ to $18.4 \%$, apparently indicating an abject failure of the government's FPS.

The Conservative-Liberal Democrat coalition government initiated an independent review of FP leading to the Hills Report (2012), which recommended a new 'Low Income-High Cost' (LIHC) FP definition. This new definition addressed some legitimate critiques of the previous definition, in particular that under the $10 \%$ definition some high income households could be classed as FP. But the main change was that, unlike its predecessor, the LIHC metric is relative: a FP household has high energy costs and a low income relative to an 'average' household. By definition, a relative FP metric will be insensitive to energy price fluctuations which affect all households, and so the headline rate of LIHC FP contains limited information about changing affordability pressures for households through time. Moreover since the LIHC FP metric is relative, eradication of FP takes on a very different meaning, and becomes very challenging.

While Hills (2012) provides a range of arguments for the LIHC metric, Figure 10 highlights some potential political benefits of the switch. First, when LIHC was introduced the rate of FP which it indicated was considerably lower than under the $10 \%$ metric. Second, its lower variation through time offers fewer striking headlines for the media. Hills (2012) did create a second indicator, the FP Gap ${ }^{46}$, which is sensitive to energy price fluctuations, but its salience in media coverage may be limited by its status as a secondary statistic.

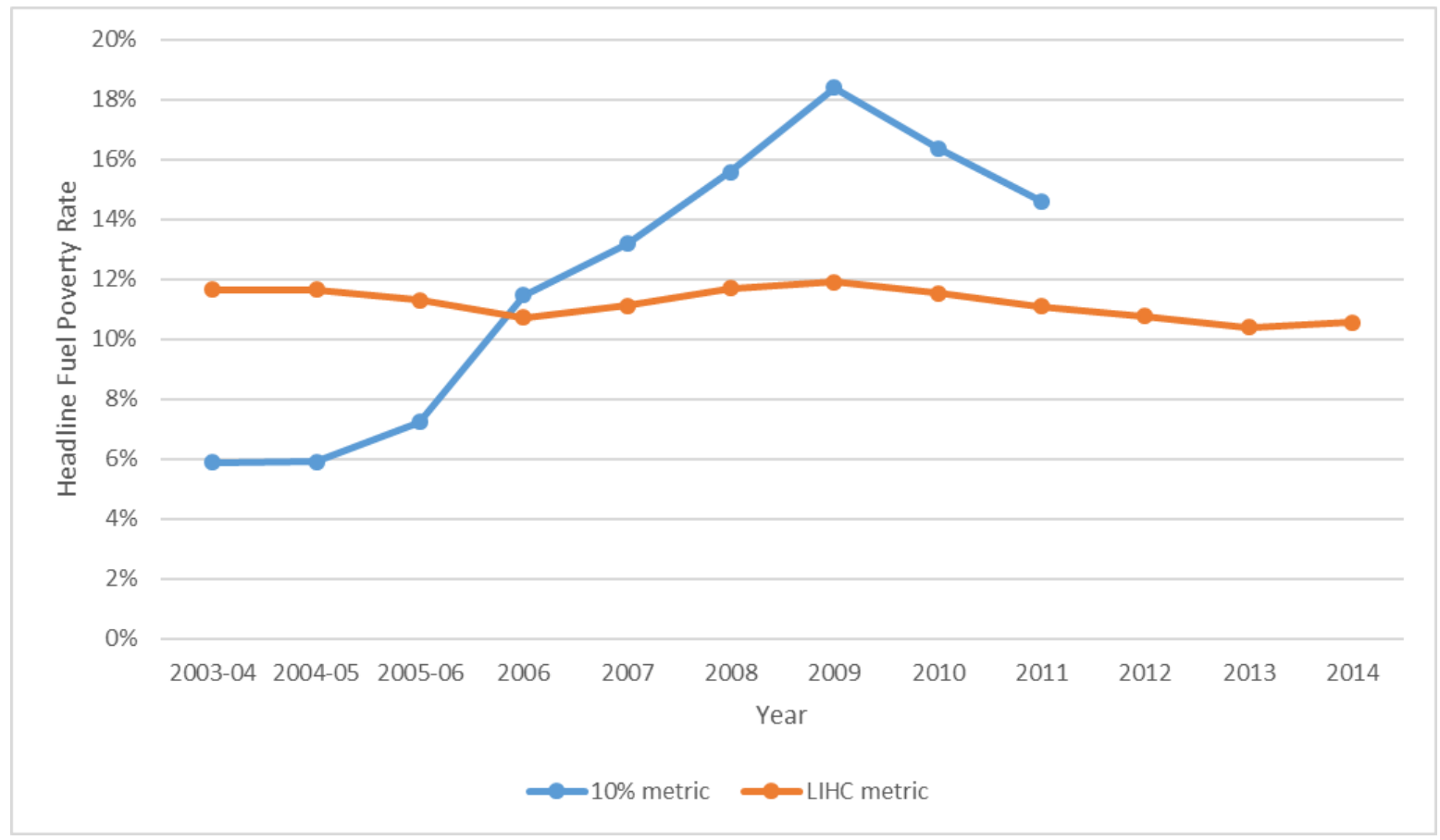

Figure 10 - Official Headline English FP Rates, 10\% and LIHC Metrics 2003-04 to $2014^{47}$

\footnotetext{
${ }^{46}$ This is the reduction in energy costs required to take a household out of LIHC FP.

47 Data for the 10\% metric is from 'Trends in Fuel Poverty, England, 2003-2011, 10\% Definition', Department for Energy and Climate Change (DECC), https://www.gov.uk/government/statistics/trends-in-fuel-povertyengland-2003-to-2011. Data for the LIHC metric is from 'Trends in Fuel Poverty, England, 2003 to 2014', Department for Energy and Climate Change (DECC), https://www.gov.uk/government/statistics/fuel-povertytrends-2003-2014
} 
Following the change in FP definition, a new FPS was published in 2015 , containing a softer target with a revised focus, namely "to ensure that as many fuel poor homes as is reasonably practicable achieve a minimum energy efficiency rating of Band C, by $2030^{\prime \prime 4}$. This target is framed in terms of energy efficiency ratings rather than households' required ENEX. While energy efficiency improvements can improve energy affordability, the relevance of this target to improving household welfare relies on a strong correlation between improved energy efficiency ratings and householders' lived experience. Good performance against this target can be achieved simply by installing energy efficiency equipment, regardless of whether it delivers real benefits to householders. A range of academic papers note the discrepancies between models of dwellings' energy efficiency and measured energy costs of individual dwellings, for example Kelly et al. (2012) and De Wilde (2014).

\subsection{Winter Fuel Payments and Other Energy Related Benefits ${ }^{49}$}

The main energy-related state benefits are WFP and Cold Weather Payments (CWP). Both are provided as additions to households' income, so their direct impact on ENEXShr is smaller than if they were regarded as reductions in energy expenditure ${ }^{50}$. We first briefly review CWP, noting their stability through much of the time period. Then we discuss WFP, and finally Warm Home Discount. We report all transfer payments in nominal terms.

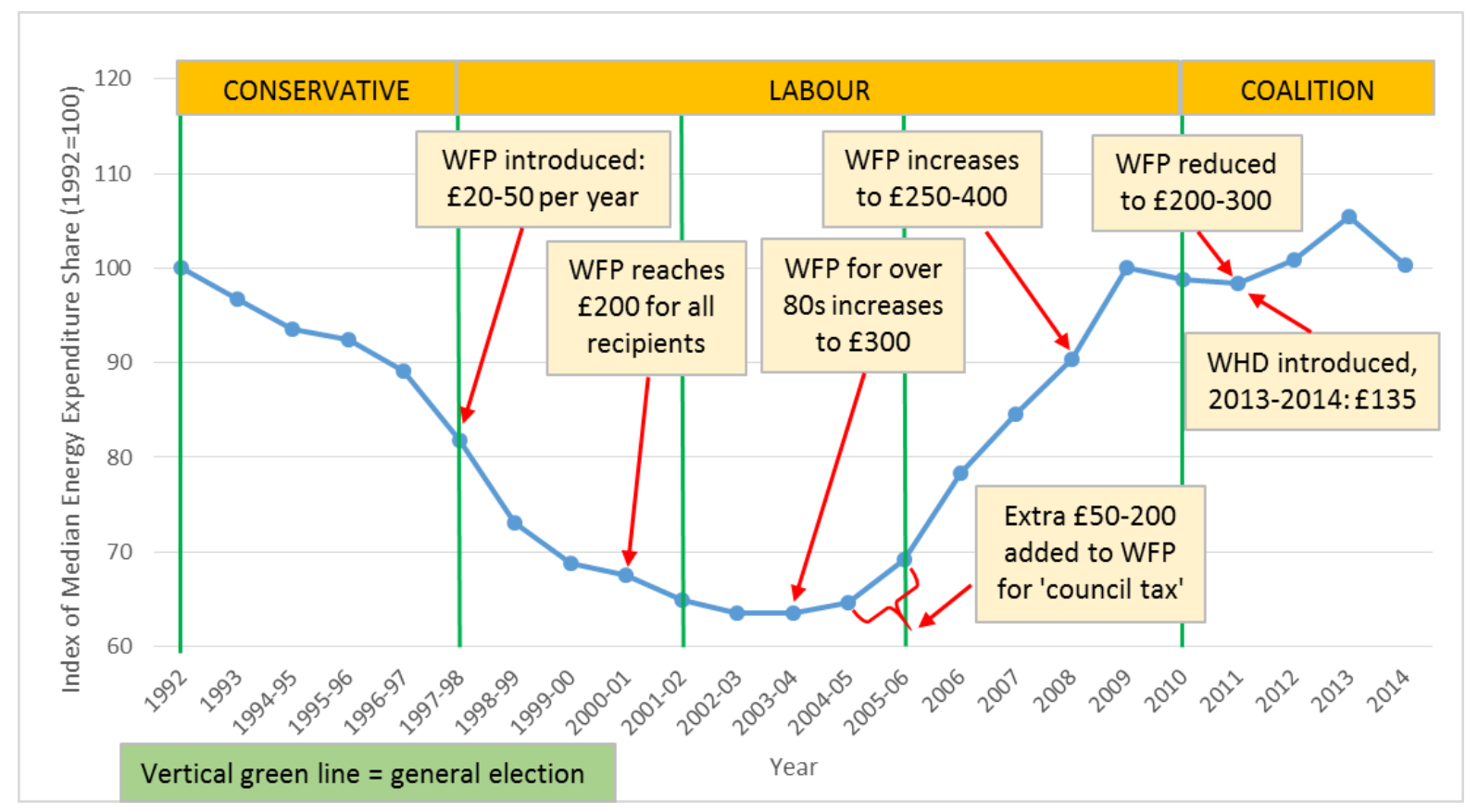

Figure 11: The evolution of the WFP and an index of median equivalised after-housing-costs ENEXShr

\subsubsection{Cold Weather Payments}

CWP was introduced in 1986 as a benefit for those on selected means tested benefits to counteract high ENEX during particularly cold weather. Payment is made when the average daily temperature at a household's location is below $0^{\circ} \mathrm{C}$ for seven consecutive days. CWP represents a risk-sharing mechanism with the government, which has greater ability to handle the financial shock of unexpected heating bills than do individual low-income households.

\footnotetext{
${ }^{48}$ See HM Government (2015).

${ }^{49}$ Detail on the timing and structure of energy transfer payments is taken from Advani et al (2013).

${ }^{50}$ An addition to the denominator (total expenditure) has less impact on a fraction's (ENEXShr) value than a deduction from the numerator (ENEX) when the denominator is considerably larger than the numerator.
} 
By 1995-96 CWP was $£ 8.50$ per qualifying week, a level constant until 2008-09, when it was increased to $f 25$. These 13 years of nominal stability resulted in the erosion of CWP's real value during the period when WFP was introduced and increased, and contributed to a substantial shift in balance from income related energy affordability support to age related support between 1997 and 2008-09. We have already noted that one group of beneficiaries, namely those aged 65-70, exhibit ENEXShr which is comparable to those in the middle rather than bottom of the equivalised after-housing-costs income distribution, raising questions about the justification for this policy shift.

\subsubsection{Winter Fuel Payments}

In 1997-98 the newly elected Labour government introduced WFP as a payment to individuals above the female pension age. In 1997-98 WFP's basic rate was $f 20$, while by 2003-04 it had experienced a tenfold increase to $f 200^{51}$; total WFP expenditure grew to $f 1$.9bn over the same period, becoming a sizable state benefit. This growth in WFP preceded the growth in ENEXShr after 2003-04 (Figure 11).

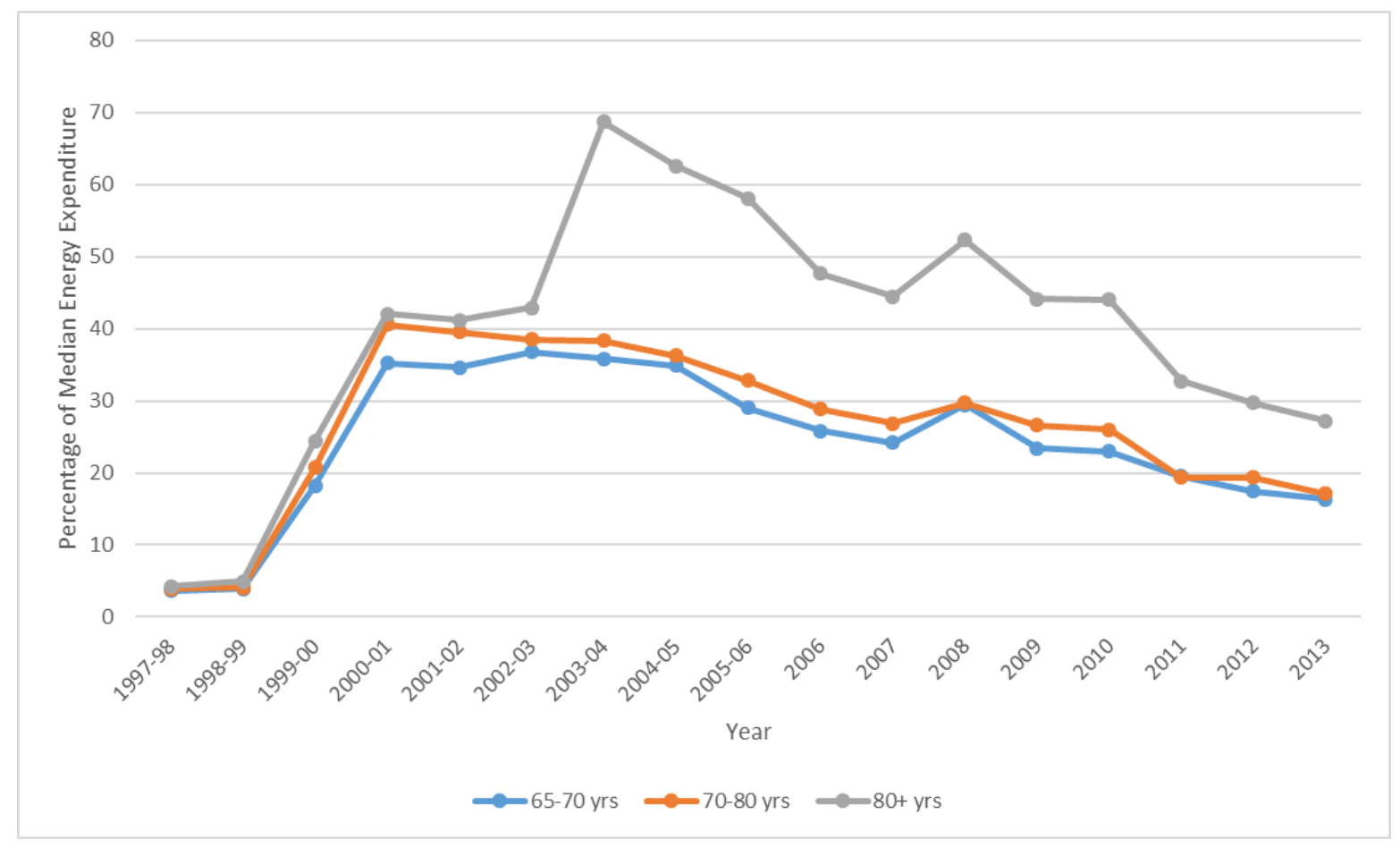

Figure 12 - WFP as Percentage of Median ENEX for Recipient Age Groups ${ }^{52}$

Figure 12 shows the main increase in WFP occurred between 1998-99 and 2000-01, with a second jump for those aged over 80 between 2002-03 and 2003-04. In 1998-99 WFP represented 3.9\% of median ENEX for households headed by someone aged 70-80, while by 2000-01 it represented 39.52\%. A smaller proportionate increase for all recipient groups occurred between 2007 and 2008. The generosity displayed in Figure 11 is even more notable as it excludes significant additional payments which were channelled through WFP in 2004-05 and 2005-0653.

\footnotetext{
${ }^{51}$ Detail on WFP's value is from Table 5.2, Advani et al (2013).

52 Median ENEX is categorised according to the household head's age.

53 In 2004-05 an extra £100 was directed through WFP to those aged 70+ to ease council tax bills (see Lourie, 2004), and in 2005-06 this was increased to $£ 200$ for all WFP recipients aged 65 or over who paid council tax (Advani et al., 2013). These additional payments were removed in 2006-07. .
} 
The elevated median ENEXShr of those aged 80+ could justify the introduction of the higher WFP rate for these households in 2003-04, initially set at $£ 300$ and representing $68.7 \%$ of median ENEX for households headed by someone over 80. In 2003-04 resources were used to increase WFP for the very old rather than to widen WFP eligibility to younger low income households, despite similarities in ENEXShr: in 2003-04 median ENEXShr for households headed by someone over 80 was $9.7 \%$, compared to $9.9 \%$ in the bottom income decile and $10.4 \%$ in the second income decile. In 2008, WFP rates were increased to $£ 400$ and $£ 250$ respectively, a move reversed in 2011 following the election of the Conservative-Liberal Democrat coalition.

Figure 13 shows that since the early 2000s household heads above the male state pension age have become a weaker proxy indicator for households on low incomes ${ }^{54}$. Between 2001-02 and 2004-05 around $55 \%$ of households with household head over 80 are estimated to be in the bottom three deciles of the equivalised after-housing-costs income, however, between 2009 and 2012 this figure had fallen to around 40\%. Similarly, between 2009 and 2014 the estimated proportion of the households with aged $65-70$ in the bottom three income deciles is below $30 \%$, i.e. there are potentially fewer households of this age in the bottom third of the equivilised after-housing-costs income distribution than in the population as a whole. Figure 13 indicates that a large part of this change occurred around the time of the Financial Crisis, suggesting it may not be that older households have become better off, but that households of working age have become relatively worse off.

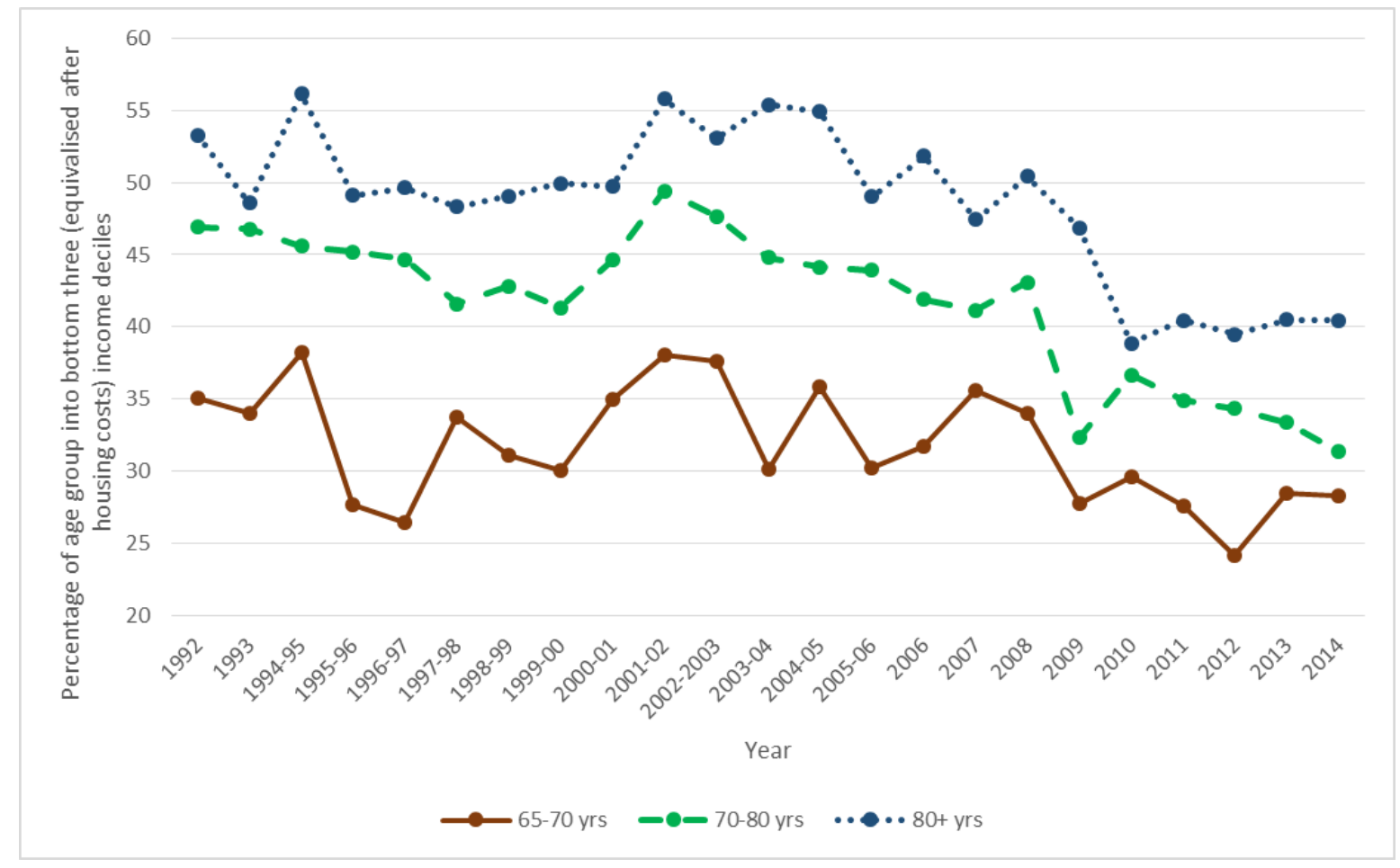

Figure 13 - Percentage of households headed by individuals of selected age groups in the bottom three deciles of the (equivalised after-housing-costs) income distribution, 1992-2014

\subsubsection{Warm Home Discount (WHD)}

The reduction in WFP in 2011 coincided with the introduction of WHD, a scheme administered by the large energy retailers ${ }^{55}$ and funded through increasing the energy prices of non-eligible consumers.

\footnotetext{
${ }^{54}$ Based on the available data in the LCF

55 Until 2019-20 only firms with more than 250,000 customers
} 
WHD therefore represents a partial 'privatisation' of energy affordability support, namely a deliberately redistributive policy mandated by government, but which avoids government expenditure..$^{56} \mathrm{WHD}$ also represents a redirection of support by benefiting two constituent groups: a 'core group' of low income pensioners ${ }^{57}$, specified by government; and a 'broader group' of low income households chosen by individual companies. While potentially advantageous for the government's fiscal position, the present structure of WHD may restrict competition in the retail energy market. Since only large companies have to provide WHD, 'core' beneficiaries may be deterred from switching to smaller suppliers, while 'broader group' beneficiaries may be additionally deterred by differences in eligibility criteria across suppliers. WHD, by reducing the financial incentives to switch supplier may explain why certain 'vulnerable' groups are less likely to switch, as noted by SSE (2015), and disputed by the CMA (2016a). This is an important factor, since consumer disengagement, i.e. a lack of switching, was the central 'problem' identified by the CMA (2016b) in its Energy Market Investigation.

\section{Concluding Remarks}

The UK's retail energy market is highly politicised, with a growing emphasis on fairness, which has led to legislation and the imposition of widespread price regulation at the end of 2018. These developments are contextualised by the present paper, which maps ENEXShr across household groups between 1992 and 2014, using a dataset incorporating a novel and significant data correction. The substantial rise in ENEXShr, and doubling of ENEX in nominal terms between 2003-04 and 2013, help to explain the sector's current political salience.

Moving beyond why the retail energy market has attracted political attention, we consider the relationship between ENEXShr and selected energy affordability policies. The key support policies, WFP and FPS, were introduced when ENEXShr were low rather than high, suggesting that increasing affordability pressures were not their main driver. Our evidence is consistent with a narrative where political expediency and ideology are driving factors in affordability support policies. First, WFP represents a shift in the balance of resources from supporting households on low incomes to those who are older, a change which is consistent with targeting support at those more likely to vote. Second, energy affordability support increased substantially under a left of centre Labour government. Third, after a large rise in affordability pressures, the Conservative led coalition government chose to redefine the measurement of FP and its alleviation target in England, potentially reducing the political salience of FP and the commitment of government to reducing its prevalence.

\section{Appendix 1 - Additional Analysis by Household Type}

In this appendix we map ENEXShr and ENEX by age of household head, tenure, household composition and UK nation. Often the ranking of ENEXShr across household groups remains relatively stable through time, despite the substantial changes to energy prices, energy affordability/fuel poverty policies and other background changes. There are two cases where groups with higher ENEXShr earlier in the period clearly converge towards other household groups: (i) single parent households relative to other families, and (ii) Northern Ireland relative to other UK nations.

\footnotetext{
${ }^{56}$ While introduced under the coalition government, WHD resulted from the Energy Act 2010 passed by the prior Labour government placing on a statutory footing a voluntary agreement regarding social tariffs between suppliers, government and Ofgem (see Hough, 2016)

57 Defined as those receiving the Guarantee Credit Element of the Pension Credit
} 


\section{A1.1 Age of Household Head}

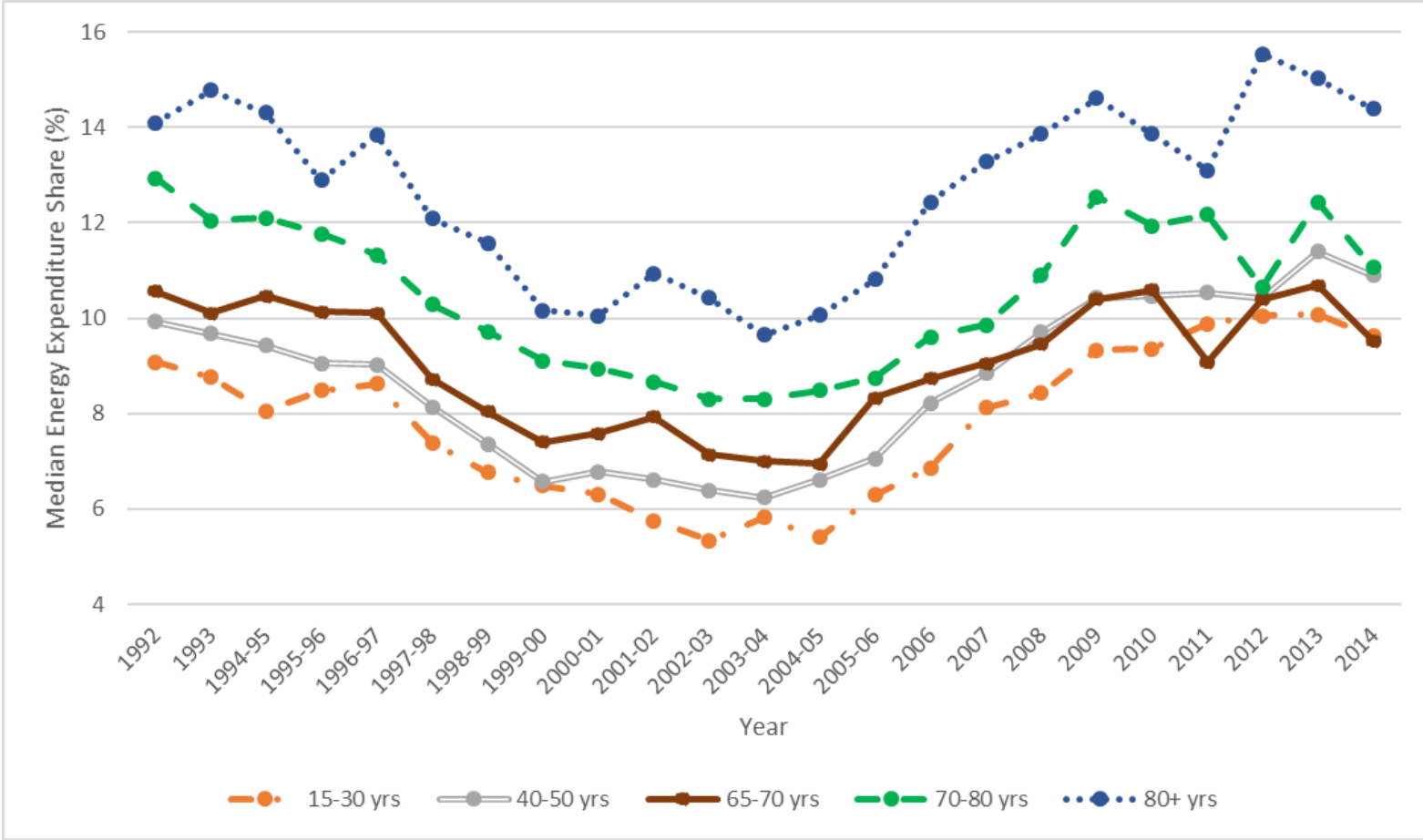

Figure A1.1 - Median (equivalised after-housing-costs) ENEXShr by age of household head (selected age categories), 1992-2014

Figure A1.1 provides evidence of the persistently elevated median ENEXShr of households headed by someone aged over 80 , providing some justification for the higher rate of WFP for those aged 80 or over. The equality of median ENEXShr between households with a head aged 70-80 and households with a head aged 80+ can be rejected at the 5\% level in all but 3 years between 1992 and 2014 . However, while in 2014 the median ENEXShr of the 80+ age group was 1.5 times that of households aged 15-30, Figure A1.2 shows that the high ENEXShr of the 80+ age group is largely due to low total expenditure (income), with these households reporting median ENEX among the lowest of all age groups. Figure A1.1 also shows some potential convergence between the ENEXShr of households headed by someone aged 65-70 and younger age groups. 


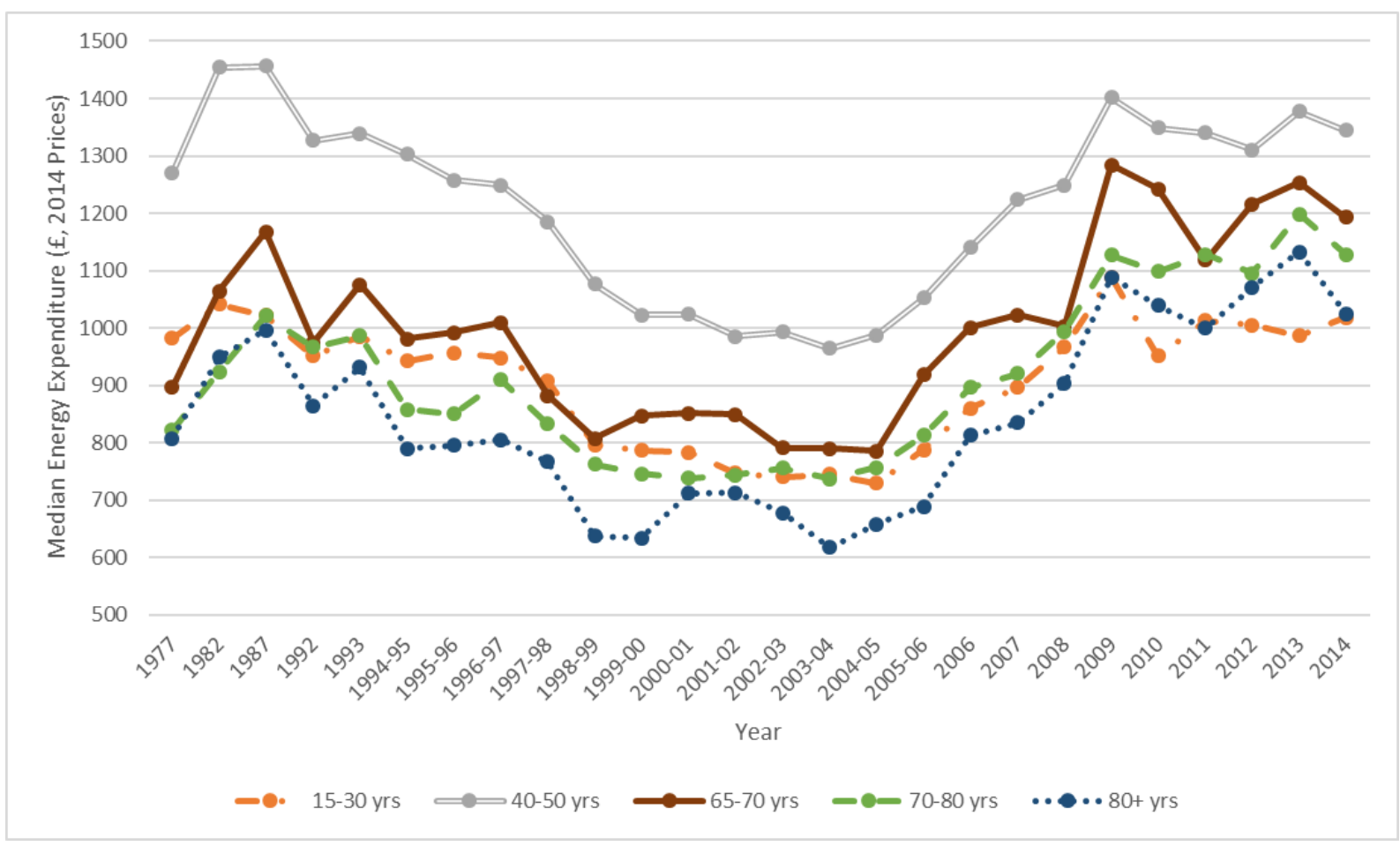

Figure A1.2 - Median ENEX by age of household head (selected age categories) in 2014 prices, 1992-2014

\section{A1.2 Tenure}

Figure A1.3 shows the median ENEXShr of those in social housing ${ }^{58}$ was persistently higher than for other tenures between 1992 and 2014; for example, the central estimate of social housing's median ENEXShr was between 3.6 and 6.2 percentage points above that for private renters ${ }^{59}$. Figure A1.4 shows that median ENEX for social housing was broadly comparable to that of private renters after 2000-01 and below that of home owners, again emphasising the role of total expenditure (income) in driving ENEXShr variations.

\footnotetext{
58 This covers both council and housing association properties.

${ }^{59}$ That the median ENEXShr of social housing and private tenants are equal is rejected at the $1 \%$ level in 1992 , 2003-04 and 2014.
} 


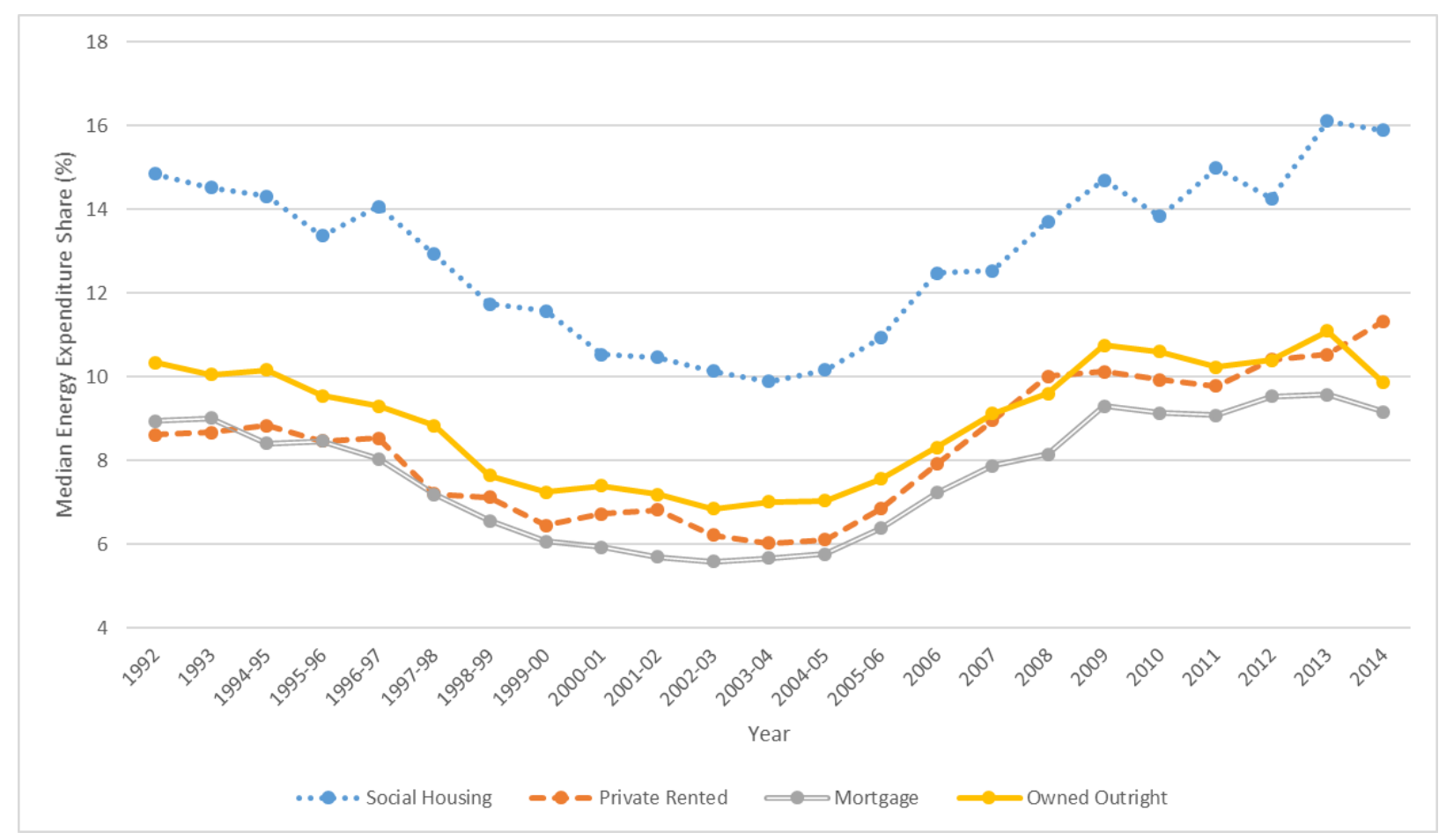

Figure A1.3 - Median (equivalised after-housing-costs) ENEXShr by tenure, 1992-2014

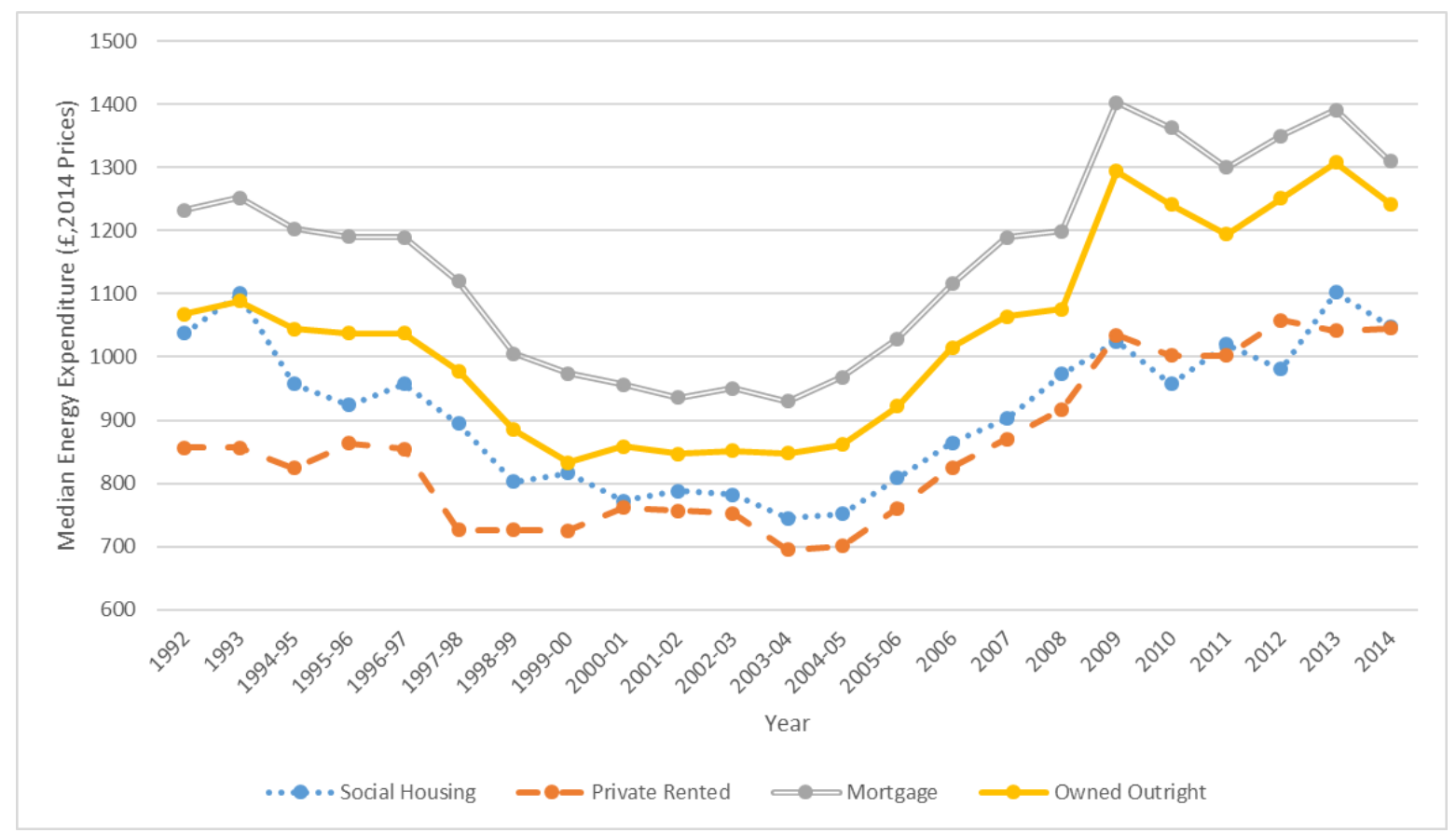

Figure A1.4 - Median (equivalised after-housing-costs) ENEX by tenure in 2014 prices, 1992-2014

\section{A1.3 Household Composition}

Median ENEXShr is generally higher for households with more members, ${ }^{60}$ but Figure A1.5 shows a significant exception is single parent households ${ }^{61}$. Households containing one adult and at least two children had a median ENEXShr above households containing two adults and at least three children.

60 This results from equivalisation and the deduction of housing costs from total expenditure.
${ }^{61}$ This term covers all households containing one adult and children. 
The median ENEXShr for these two household types is significantly different at the 1\% level in 1992 and 2003-04, though not in 2014. The lack of significance in 2014 reflects the apparent convergence between single parents' ENEXShr and other families of similar size over time in Figure A1.5. The lower median ENEX for households containing one adult and at least two children shown in Figure A1.6 suggests that lower total expenditure (income) explains the higher ENEXShr of single parent households.

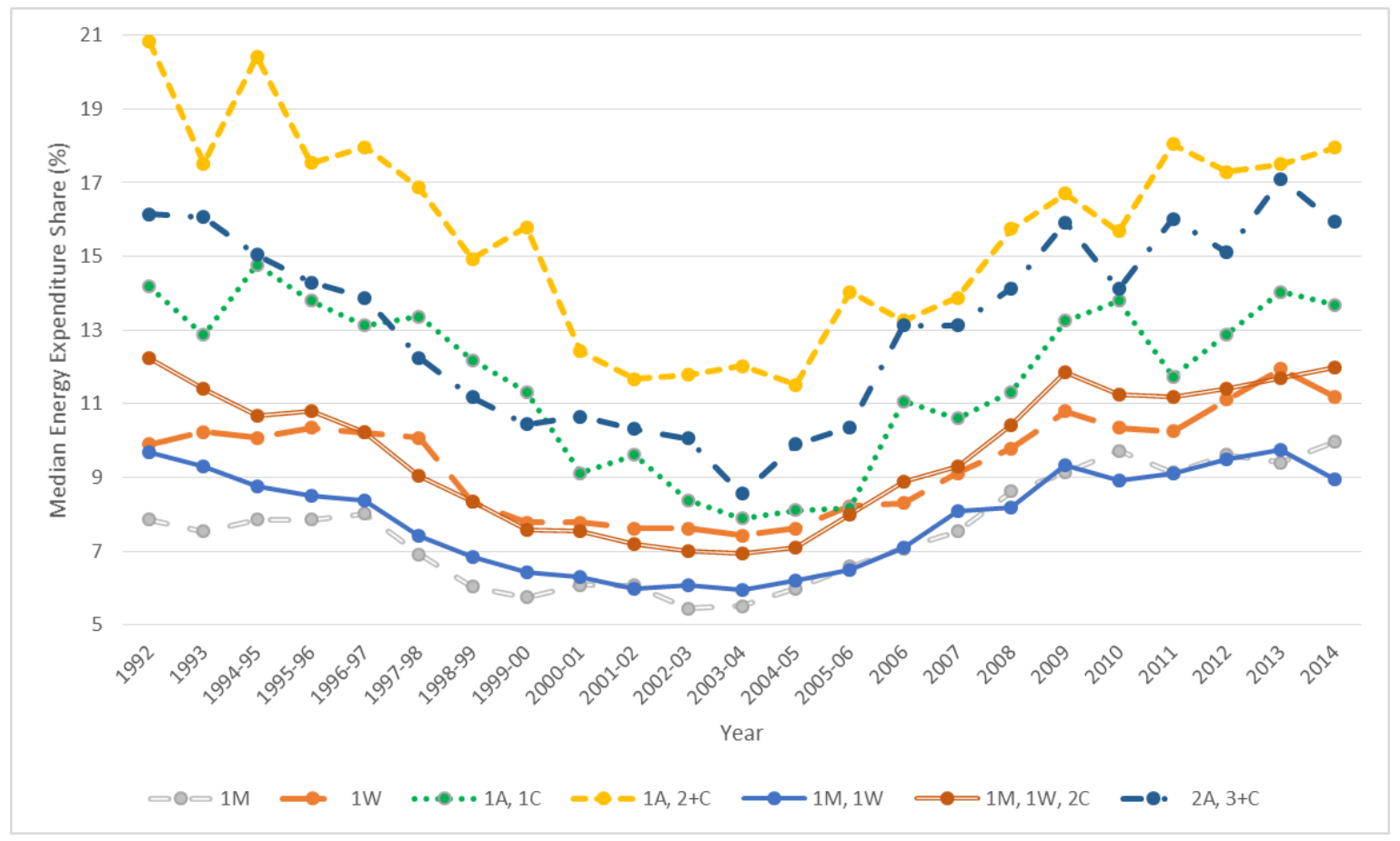

Figure A1.5 - Median (equivalised after-housing-costs) ENEXShr for selected household compositions, 1992 2014

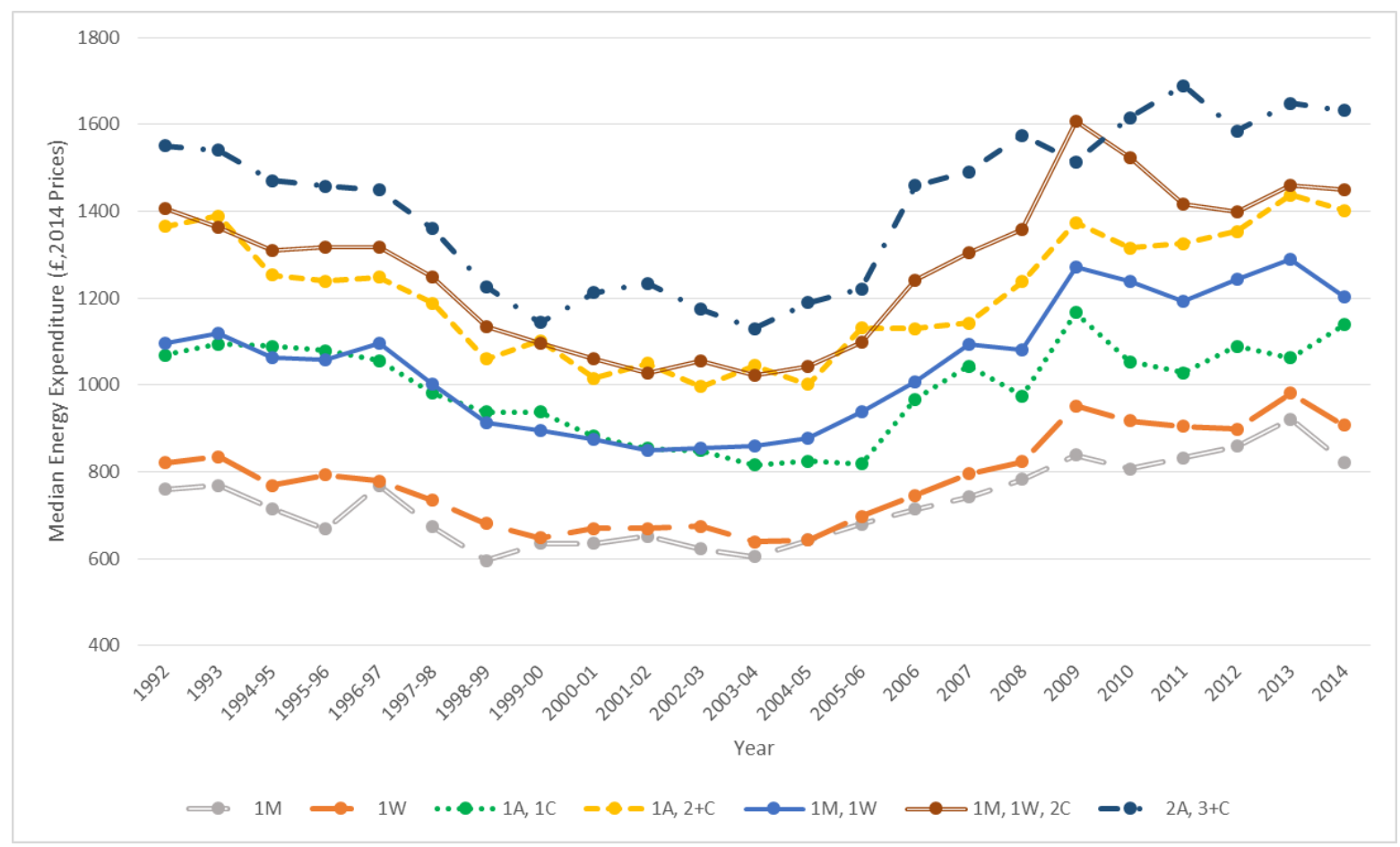

Figure A1.6 - Median ENEX for selected household compositions in 2014 prices, 1992-2014 
Regarding the convergence of single parents' ENEXShr to other households, there is a possible structural break in single parent households ENEXShr between 1999-00 and 2000-01. This is particularly visible in Figure A1.7 where the median ENEXShr for different household compositions are reported as a multiple of the median ENEXShr for a single male. Between 1999-00 and 2000-01 the median ENEXShr of households containing one adult and one child fell by 2.2 percentage points and the median ENEXShr of households containing one adult and at least two children fell by 3.4 percentage points, while the median ENEXShr of other household compositions remained broadly flat. Of the household compositions in Figure A1.6, statistical tests consistently reject the equality of median ENEXShr in 1999-00 and 2000-01 only for the two types of single parent households. However, the statistical tests generally do not reject the equality of median ENEX (Figure A1.6) ${ }^{62}$ for these single parent households in 1999-00 and 2000-01, suggesting that the decrease in single parents' ENEXShr results from an increase in their total expenditure (income). A contribution to this income increase may have been the introduction of the Working Families Tax Credit during 1999-2000. ${ }^{63}$

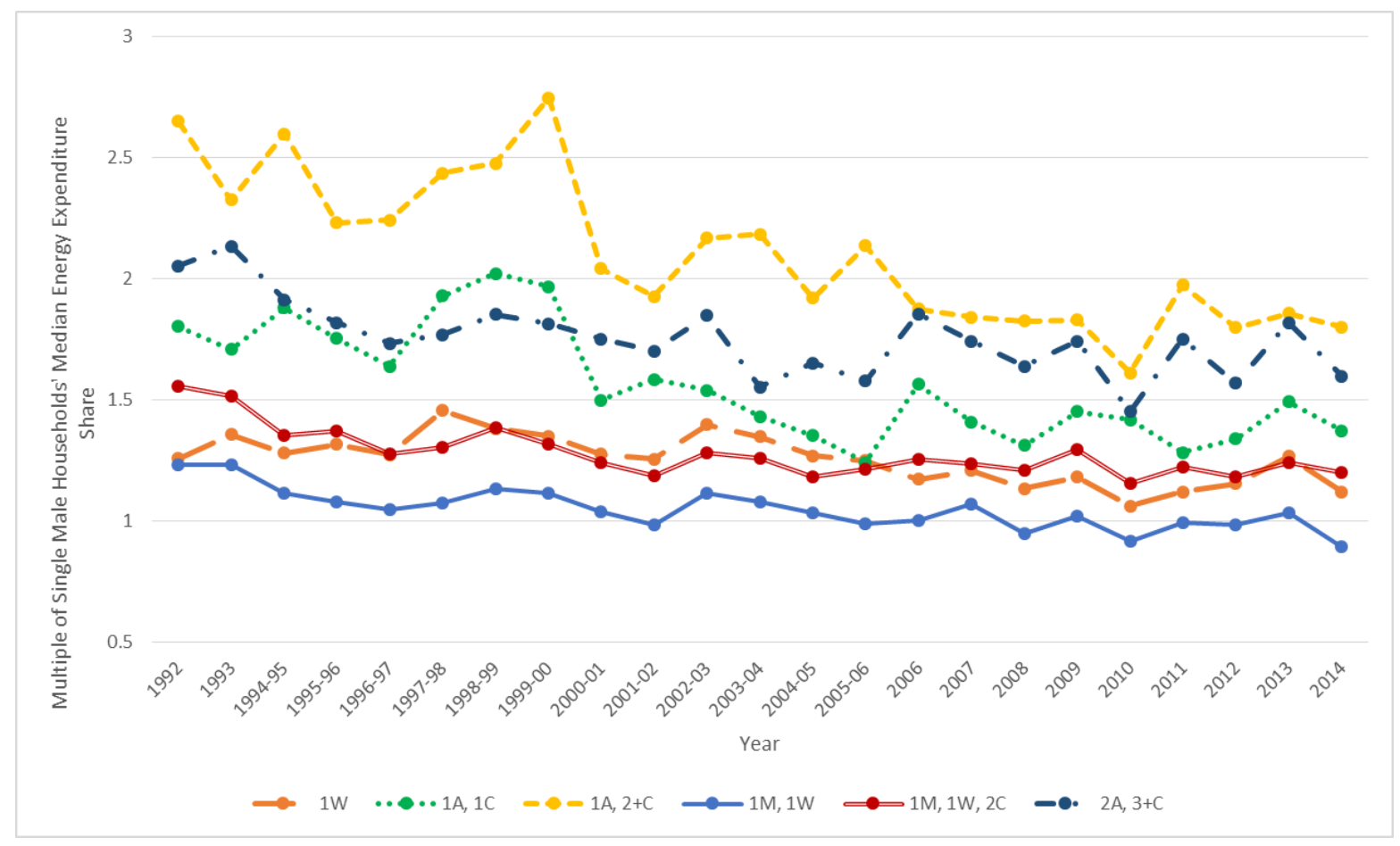

Figure A1.7 - Median (equivalised after-housing-costs) ENEXShr of selected household compositions as multiples of a single male's median (equivalised after-housing-costs) ENEXShr, 1992-2014

\section{A1.4 Devolved administrations}

The main feature of median ENEXShr by devolved administrations in Figure A1.8 is convergence between Northern Ireland and other UK nations between 1982 and 1992, even though median ENEX remained elevated in Northern Ireland for most of the time period (see Figure A1.9). For example, median ENEX in Northern Ireland was $£ 1656$ compared to $f 1229$ in Wales in $2014^{64}$, while the ENEXShr of these two devolved administrations were $12.3 \%$ and $12.5 \%$ respectively. In 2014 the equivalence of median ENEX between Northern Ireland and Wales could be rejected at the $1 \%$ level, but equivalence of median ENEXShr could not be rejected. In contrast, in 1982, the equivalence of both

\footnotetext{
62 Where the equality of median ENEX is rejected this occurs only at the $10 \%$ level

63 pg 12, Blundell and Hoynes (2001) discusses this policy's impact.

${ }^{64}$ Equality of the median ENEX of Wales and Northern Ireland in 2014 could be rejected at the $1 \%$ level.
} 
median ENEX and median ENEXShr between Northern Ireland and Wales could be rejected at the $1 \%$ level.

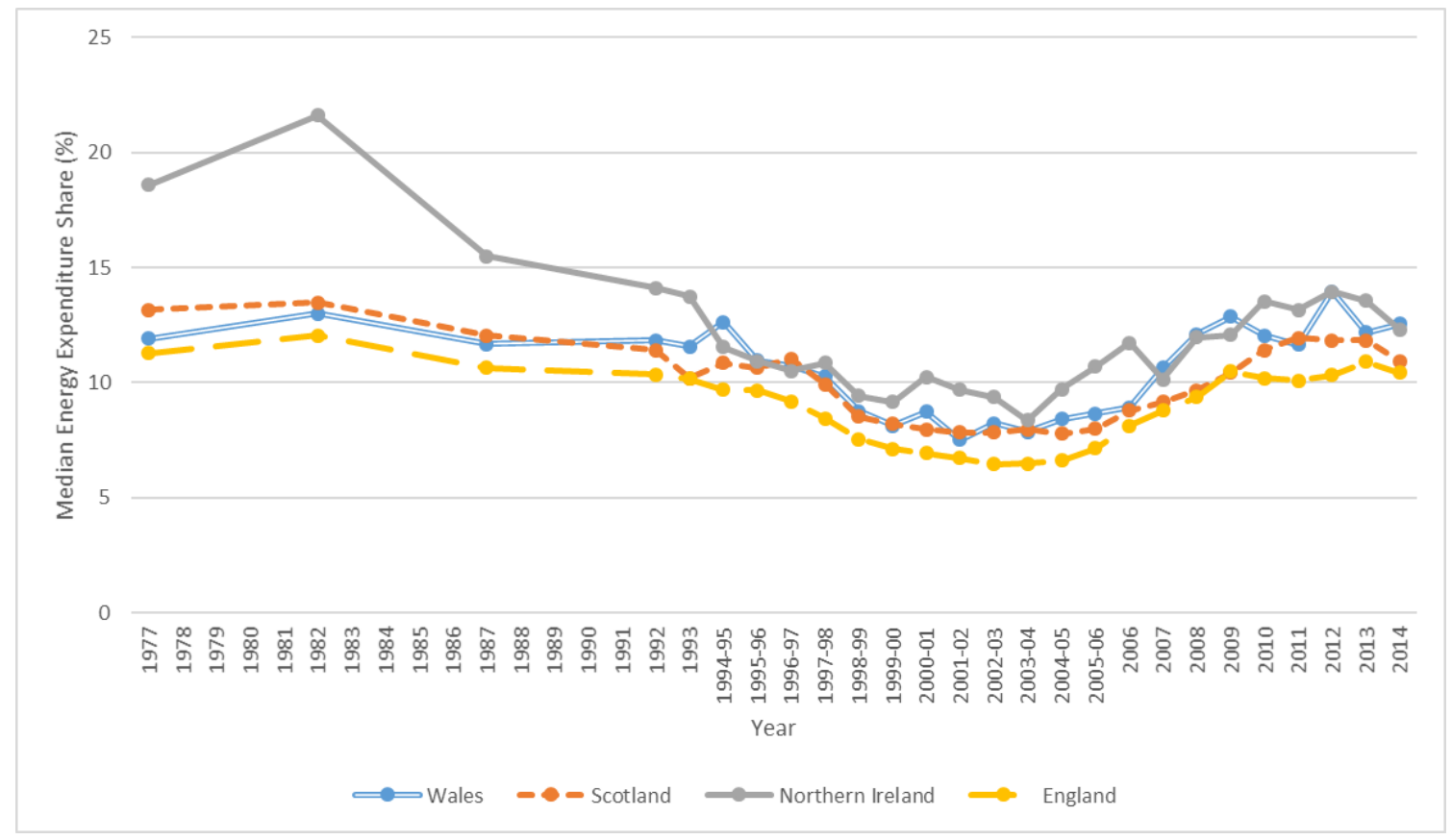

Figure A1.8 - Median (equivalised after-housing-costs) ENEXShr by devolved administration, 1977-2014

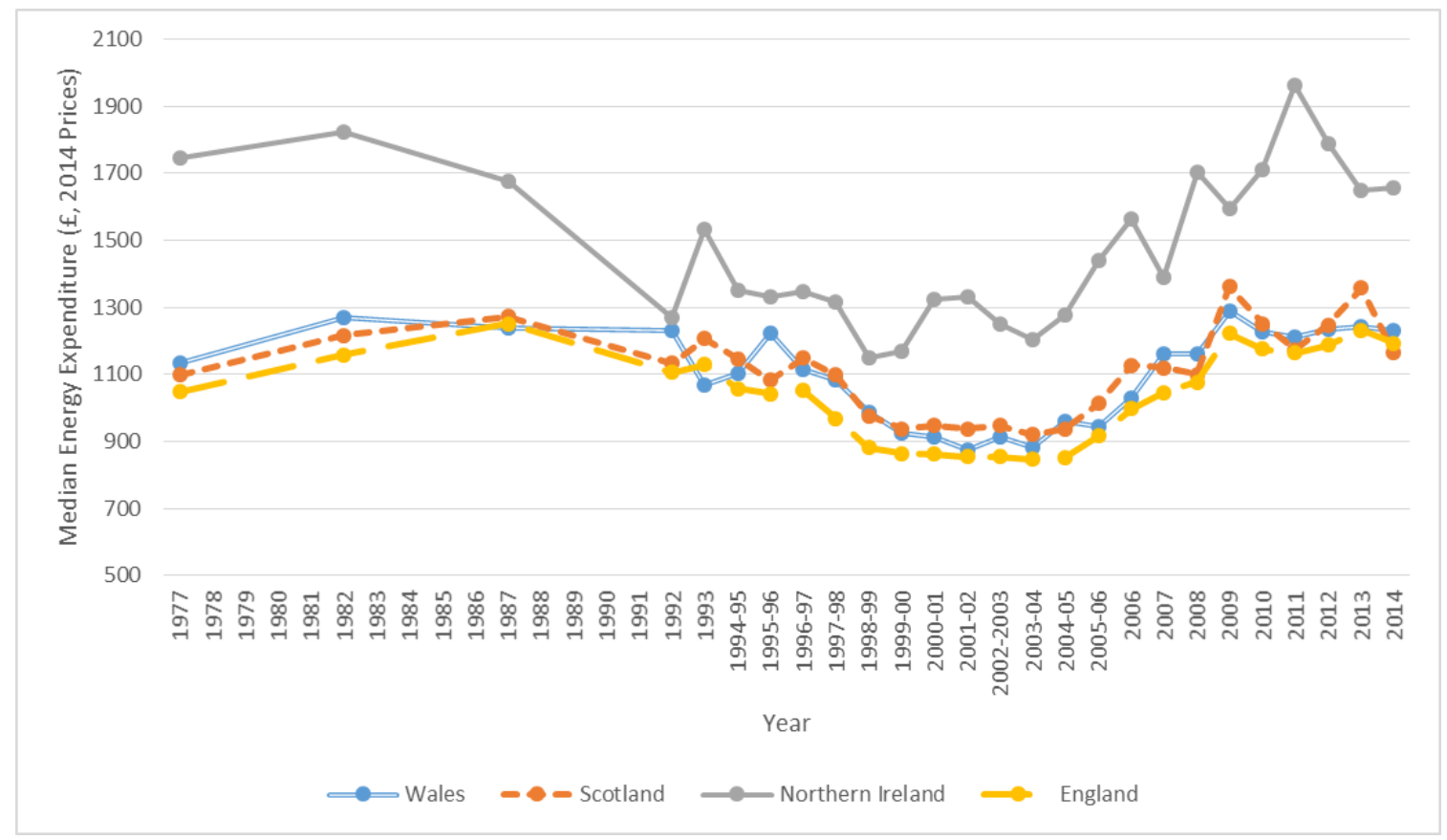

Figure A1.9 - Median ENEX by devolved administration, 1977-2014 


\section{Appendix 2 - Additional Materials}

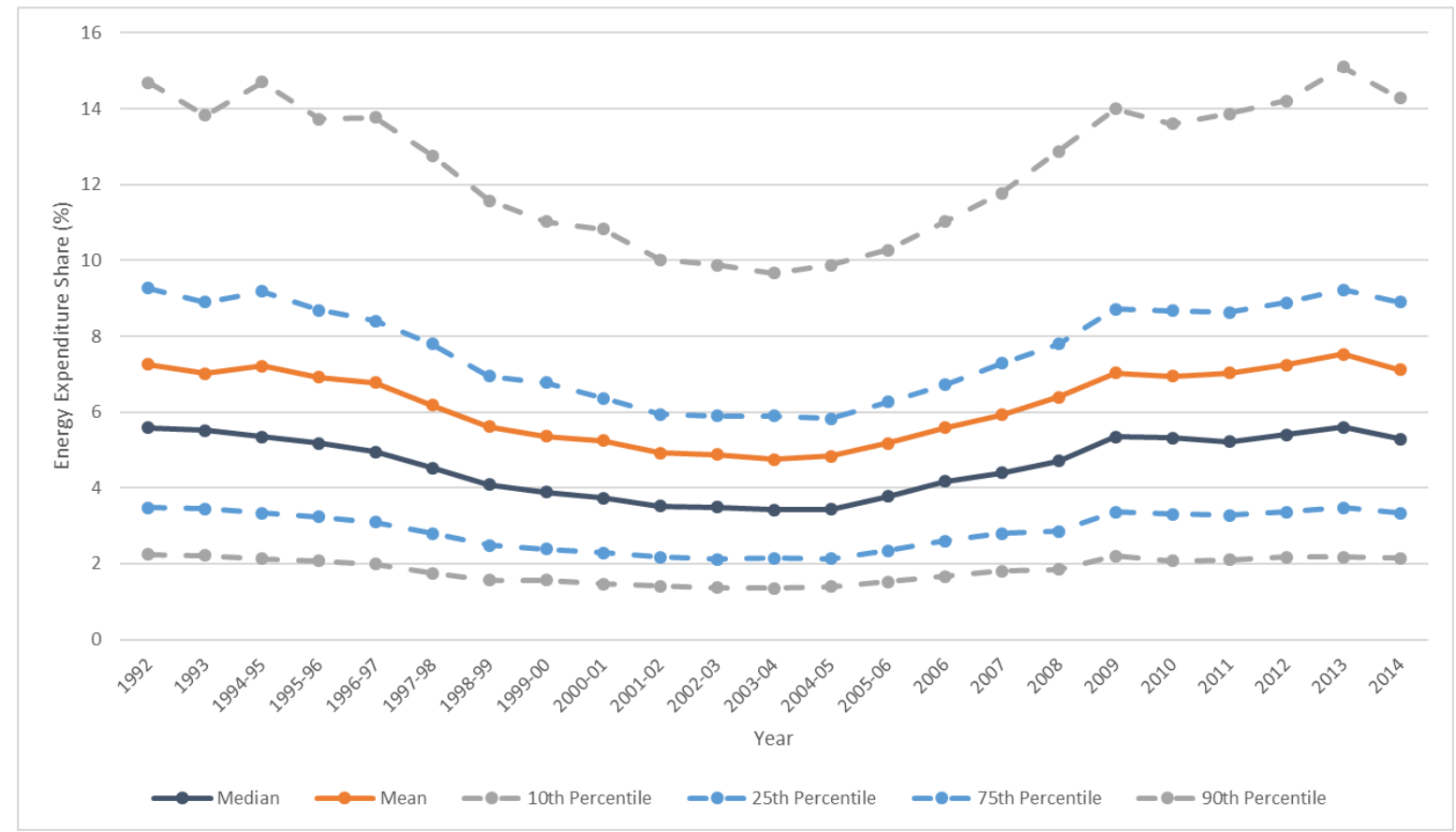

Figure A2.1 - ENEXShr distribution, 1992-2014 (unequivalised and including housing costs)

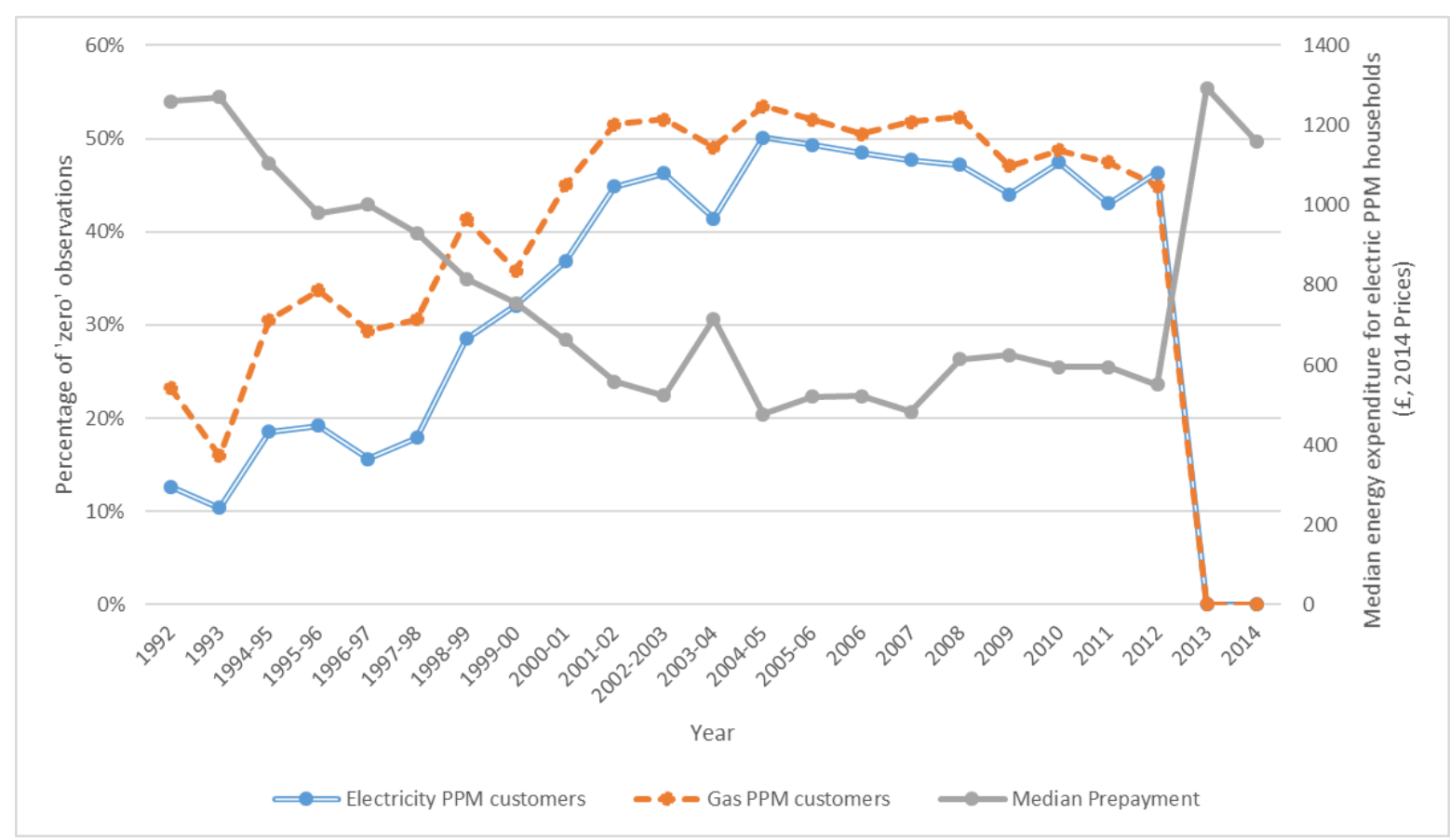

Figure A2.2 - Percentage of PPM customers with zero expenditure plotted against median ENEX ${ }^{65}$ (2014 prices) for electricity PPM customers

${ }^{65}$ Here ENEX is ' $r a w^{\prime}$, i.e. before weighting and the seasonality correction are applied. 


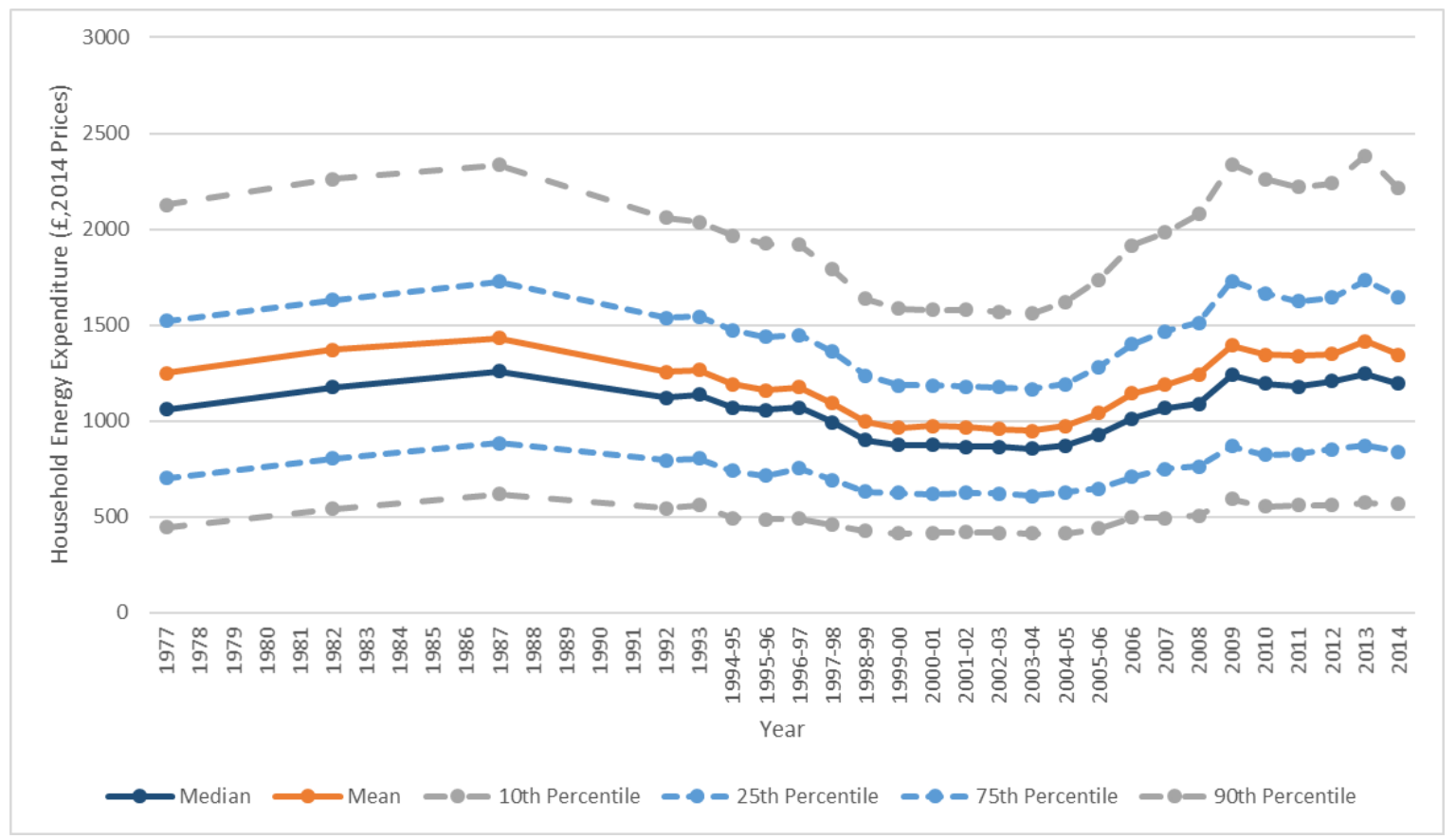

Figure A2.3 - Household ENEX distribution in 2014 prices, 1977-2014

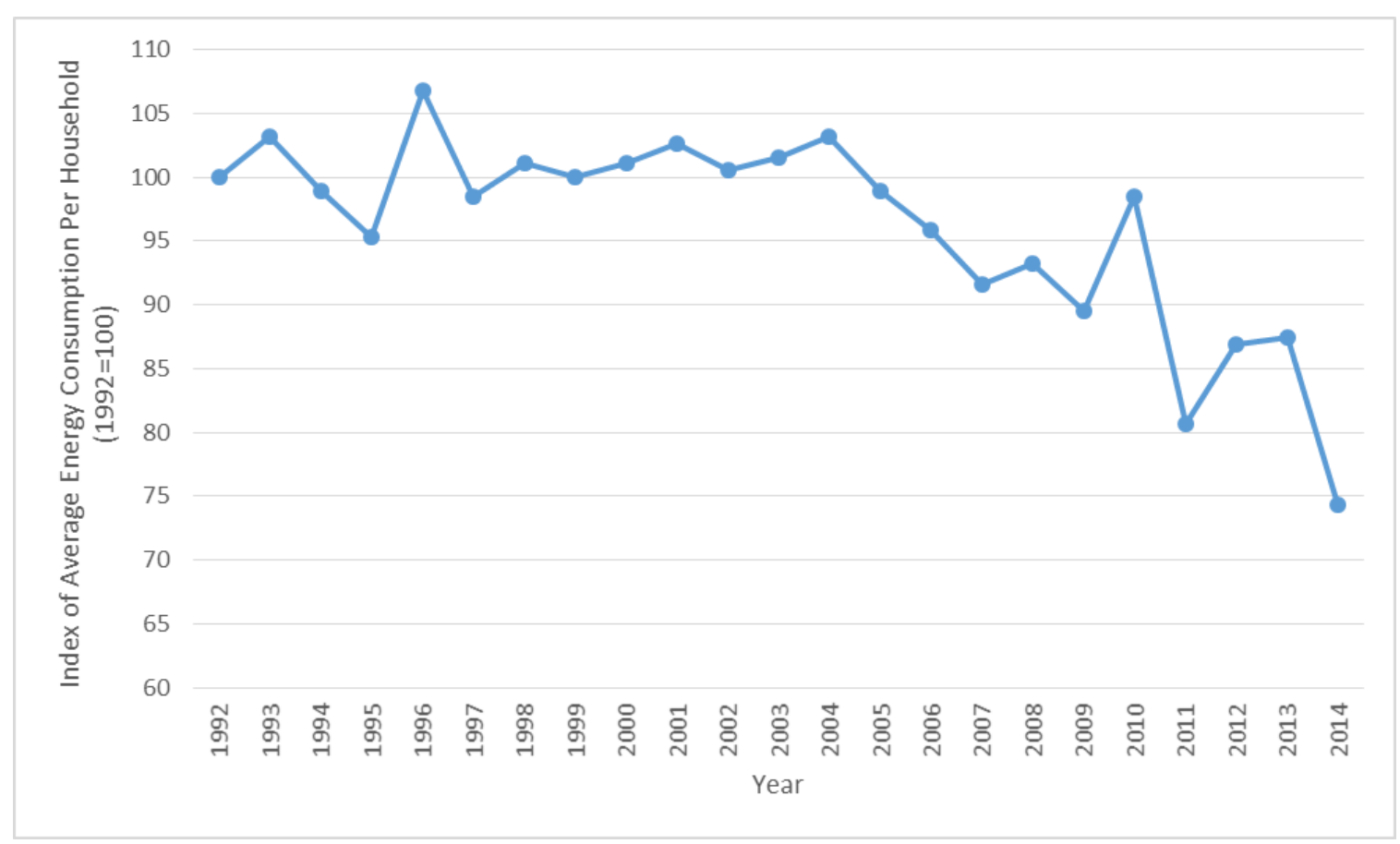

Figure A2.4 - Index of average energy consumption per household (1992=100), 1992-2014 ${ }^{66}$

${ }^{66}$ Data from Table 3.04, Energy Consumption in the UK (ECUK) 2016 Data Tables, Department for Business, Energy and Industrial Strategy, https://www.gov.uk/government/statistics/energy-consumption-in-the-uk. 


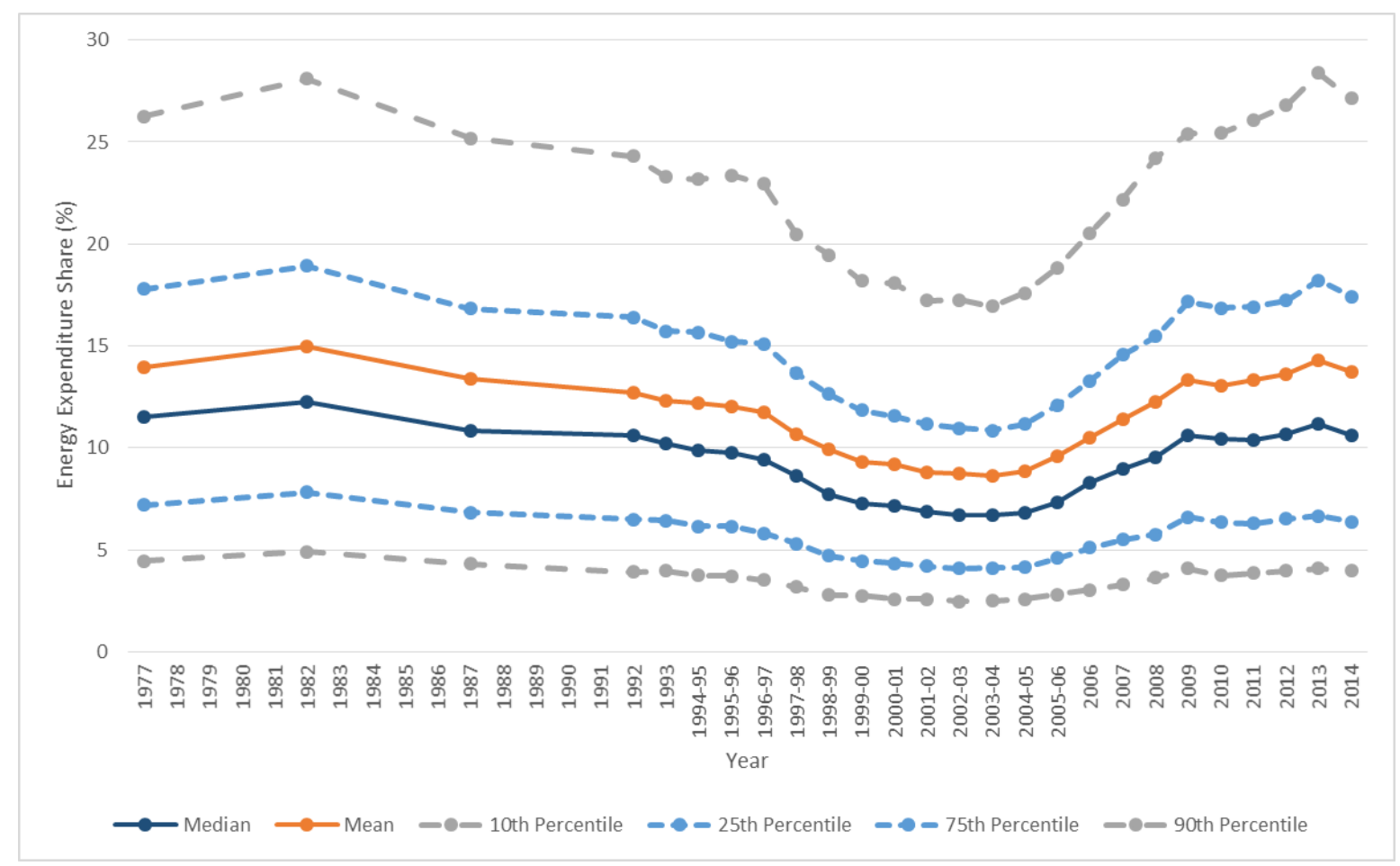

Figure A2.5 - ENEXShr (equivalised and after-housing-costs) distribution, 1977-2014

\section{References}

Advani, A., P. Johnson, A. Leicester and G. Stoye (2013), 'Household Energy Use in Britain: A Distributional Analysis', IFS Report R85, Institute for Fiscal Studies, London, United Kingdom

Baker, P., R. Blundell and J. Micklewright (1989), 'Modelling Household Energy Expenditures Using Micro-Data', Economic Journal, 99(397), pp. 720-738

Baker, P. and R. Blundell (1991), 'The Microeconometric Approach to Modelling Energy Demand: Some Results for UK Households', Oxford Review of Economic Policy, 7(2), pp. 54-76

Boardman, B. (1991), 'Fuel poverty - from cold homes to affordable warmth', Belhaven Press, London, United Kingdom

Blundell, R. and H. Hoynes (2001), 'Has “In-Work" Benefit Reform Helped the Labour Market?', NBER Working Paper 8546, National Bureau of Economic Research, Cambridge, Massachusetts, available at: http://www.nber.org/papers/w8546.pdf

Brewer, M. and C. O'Dea (2012), 'Measuring living standards with income and consumption: evidence from the UK', Institute of Social and Economic Research, ISER Working Paper Series No. 2012-05, available at: https://www.econstor.eu/bitstream/10419/65998/1/688939007.pdf

Buchs, M. and S.V. Schnepf (2013a), 'Who emits most? Associations between socio-economic factors and UK households' home energy, transport, indirect and total CO2 emissions', Ecological Economics, 90, pp. 114-123

Buchs, M. and S.V. Schnepf (2013b), 'Expenditure as proxy for UK household emissions? Comparing three estimation methods', Working Paper A13/02 Applications and Policy, Southampton Statistical Sciences Research Institute, University of Southampton, Southampton, United Kingdom, available at: https://eprints.soton.ac.uk/353066/ 
Chatterton, T.J., J. Anable, J. Barnes and G. Yeboah (2016), 'Mapping household direct energy consumption in the United Kingdom to provide a new perspective on energy justice', Energy Research and Social Science, 18, pp. 71-87

Competition and Markets Authority (2016a), 'Appendix 8.7: Demographic characteristics and commentary on certain SSE and RWE analysis', 'Energy Market Investigation: Final Report', 24 June 2016, London, United Kingdom, available at: https://assets.publishing.service.gov.uk/media/576bcbb040f0b66bda0000ae/appendix-8-7demographic-characteristics-and-commentary-on-sse-rwe-analysis-fr.pdf

Competition and Markets Authority (2016b), 'Energy market investigation: Summary of final report', 24 June 2016, London, United Kingdom, available at: https://assets.publishing.service.gov.uk/media/576c23e4ed915d622c000087/Energy-finalreport-summary.pdf

Crawford, I., S. Smith and S. Webb (1993), 'VAT on Domestic Energy', Institute for Fiscal Studies, London, United Kingdom, available at: http://discovery.ucl.ac.uk/17291/1/17291.pdf

Deller, D. (2016), 'Energy Affordability in the EU: The Risks of Metric Driven Policies', CCP Working Paper 16-9, Centre for Competition Policy, Norwich, United Kingdom, available at: http://competitionpolicy.ac.uk/documents/8158338/11320618/CCP+WP+16-

9+complete.pdf/69d1f4ff-7301-493d-a255-4de8d92b2280

Deller, D. and C. Waddams Price (2018), 'Comparing English Fuel Poverty Rates: Reported vs Modelled Expenditure', CCP Working Paper 18-X, Centre for Competition Policy, University of East Anglia, Norwich

Department of Energy and Climate Change (DECC) (2014), 'Annual Fuel Poverty Statistics Report, 2014', London, United Kingdom, available at: https://www.gov.uk/government/uploads/system/uploads/attachment_data/file/319280/Fuel_P overty_Report_Final.pdf

Department for Environment, Food and Rural Affairs (DEFRA) (2004), 'Fuel Poverty in England: The Government's Plan for Action', London, United Kingdom, available at: http://www.cumbria.gov.uk/elibrary/Content/Internet/535/6032/6036/6037/40438154224.pdf

De Wilde, P. (2014), 'The gap between predicted and measured energy performance of buildings: A framework for investigation', Automation in Construction, 41, pp. 40-49

Dimitropoulos, J., L.C. Hunt and G. Judge (2005), 'Estimating underlying energy demand trends using UK annual data', Applied Economic Letters, 12(4), pp. 239-244

Dresner, S. and P. Ekins (2006), 'Economic Instruments to Improve UK Home Energy Efficiency without Negative Social Impacts', Fiscal Studies, 27(1), pp. 47-74

Druckman, A. and T. Jackson (2008), 'Household energy consumption in the UK: A highly geographically and socio-economically disaggregated model', Energy Policy, 36, pp. 3177-3192

Fahmy, E., J. Thumim and V. White (2011), 'The distribution of UK Household CO2 emissions: Interim report', JRF programme paper: Climate change and social justice, Joseph Rowntree Foundation, available at: https://www.jrf.org.uk/report/distribution-uk-household-co2-emissions

Gough, I., S. Abdallah, V. Johnson, J. Ryan-Collins and C. Smith (2011), 'The distribution of total greenhouse gas emissions by households in the UK, and some policy implications for social policy', 
CASE/152, July 2011, Centre for Analysis of Social Exclusion, London School of Economics, London, United Kingdom, available at: http://sticerd.Ise.ac.uk/dps/case/cp/CASEpaper152.pdf

Hargreaves, K., I. Preston, V. White and J. Thumim (2013), 'The Distribution of Household CO2 Emissions in Great Britain', Supplementary Project Paper No. 1, JRF Programme Paper - Climate change and social justice, March 2013, York, United Kingdom, available at: https://www.jrf.org.uk/report/distribution-household-co2-emissions-great-britain

Hills, J. (2012), 'Getting the measure of fuel poverty - Final Report of the Fuel Poverty Review', Centre for Analysis of Social Exclusion, CASE report 72, London, United Kingdom, available at: https://www.gov.uk/government/uploads/system/uploads/attachment_data/file/48297/4662getting-measure-fuel-pov-final-hills-rpt.pdf

Hirsch, D., I. Preston, and V. White (2011), 'Understanding fuel expenditure: Fuel poverty and spending on fuel', Centre for Sustainable Energy, Bristol, United Kingdom, available at: https://www.cse.org.uk/downloads/reports-and-publications/fuel-poverty/understanding-fuelexpenditure.pdf

HM Government (2015), 'Cutting the cost of keeping warm: A fuel poverty strategy for England', URN 15D/062, March 2015, London, United Kingdom, available at: https://www.gov.uk/government/uploads/system/uploads/attachment_data/file/408644/cuttin g_the_cost_of_keeping_warm.pdf

Hough, D. (2016), 'The Warm Home Discount Scheme', House of Commons Library Briefing Paper, Number SN 05956, 6 May 2016, available at: http://researchbriefings.files.parliament.uk/documents/SN05956/SN05956.pdf

Isherwood, B.C. and R.M. Hancock (1979), 'Household Expenditure on Fuel: Distributional Aspects', Economic Advisor's Office, Department for Health and Social Security, London, United Kingdom

Kelly, S., D. Crawford-Brown and M.G. Pollitt (2012), 'Building performance evaluation and certification in the UK: Is SAP fit for purpose?', Renewable and Sustainable Energy Reviews, 16(9), pp. 6861-6878

Kidson, M. and E. Norris (undated), 'Implementing the Fuel Poverty Strategy', Institute for Government, available at: https://www.instituteforgovernment.org.uk/sites/default/files/publications/Implementing\%20th e\%20Fuel\%20Poverty\%20Strategy\%20-\%20final_0.pdf

Levell, P. and Z. Oldfield (2011), 'The spending patterns and inflation experience of low-income households over the past decade', Institute for Fiscal Studies, IFS Commentary C119, London, United Kingdom, available at: https://www.ifs.org.uk/comms/comm119.pdf

Lourie, J. (2004), 'Age-Related Payments Bill: Bill 92 of 2003-04', House of Commons Library, Research Paper 04/34, 29 April 2004, available at: http://researchbriefings.files.parliament.uk/documents/RP04-34/RP04-34.pdf

Meier, H., T. Jamasb and L. Orea (2013), 'Necessity or Luxury Good? Household Energy Spending and Income in Britain 1991-2007', The Energy Journal, 34(4), pp. 109-128

Meier, H. and K. Rehdanz (2010), 'Determinants of residential space heating expenditures in Great Britain', Energy Economics, 32(5), pp. 949-959 
Mummery, H. and H. Reilly (2010), 'Cutting back, cutting down, cutting off - Self-disconnection among prepayment meter users', Consumer Focus, July 2010, available at: http://webarchive.nationalarchives.gov.uk/20130103083536/http://www.consumerfocus.org.uk /publications/cutting-back-cutting-down-cutting-off

Ofgem (2016), 'Domestic Suppliers' Social Obligations: 2015 annual report', London, United Kingdom, available at: https://www.ofgem.gov.uk/system/files/docs/2016/10/social obligations report 2015.pdf

Ofgem (2017), 'State of the Energy Market: 2017 Report', London, United Kingdom, available at: https://www.ofgem.gov.uk/system/files/docs/2017/10/state of the market report 2017 web 1.pdf

Scottish and Southern Energy (SSE) (2015), 'Annex 2: Vulnerable Customers Statistical Analysis Frontier Economics', 'SSE: Response to Provisional Findings', 5 August 2015, available at: https://assets.publishing.service.gov.uk/media/55eda6da40f0b61526000001/SSE_resp_to_PFs.p df

Thumim, J. and V. White (2008), 'Distributional Impacts of Personal Carbon Trading - Final Report to the Department for Environment, Food and Rural Affairs', Department for Environment, Food and Rural Affairs, March 2008, London, United Kingdom, available at: https://www.cse.org.uk/downloads/reports-and-publications/policy/energyjustice/distributional-impacts-carbon-trading.pdf

Vyas, D. (2014), 'Topping-up or dropping-out: self-disconnection among prepayment meter users', Citizens Advice Bureau report, available at: https://www.citizensadvice.org.uk/global/migrated_documents/corporate/topping-up-ordropping-out.pdf

Waddams, C., M. Giulietti, D. Sharratt, A. Ferrari and D. Cooke (2001), 'Affording Gas and Electricity: Self Disconnection and Rationing by Prepayment and Low Income Credit Consumers and Company Attitudes to Social Action', March 2001, Report for the Electricity Association, Centre for Management under Regulation/Centre for Competition and Regulation, University of Warwick/University of East Anglia available at: http://competitionpolicy.ac.uk/documents/8158338/8264975/1.106645\%21electricity+associatio n+full+report+2001.pdf/28ebd098-787f-44ad-9f0d-9baae91c57cf

Waddams, C. and D. Deller (2015), 'Affordability of utilities' services: extent, practice, policy', a report for the Centre on Regulation in Europe (CERRE), Brussels, Belgium, available at: http://www.cerre.eu/sites/cerre/files/Affordability_FinalReport.pdf 